\title{
WestVirginiaUniversity
}

THE RESEARCH REPOSITORY @ WVU

Faculty \& Staff Scholarship

2019

\section{Speaking for "Free": Word of Mouth in Free- and Paid-Product Settings}

Samuel Bond

Georgia Institute of Technology, samuel.bond@scheller.gatech.edu

Stephen He

West Virginia University, stephen.he@mail.wvu.edu

Wen Wen

University of Texas at Austin, wen.wen@mccombs.utexas.edu

Follow this and additional works at: https://researchrepository.wvu.edu/faculty_publications

Part of the Cognition and Perception Commons, Cognitive Psychology Commons, E-Commerce Commons, Marketing Commons, and the Social Psychology Commons

\section{Digital Commons Citation}

Bond, Samuel; He, Stephen; and Wen, Wen, "Speaking for "Free": Word of Mouth in Free- and Paid-Product Settings" (2019). Faculty \& Staff Scholarship. 3041.

https://researchrepository.wvu.edu/faculty_publications/3041

This Article is brought to you for free and open access by The Research Repository @ WVU. It has been accepted for inclusion in Faculty \& Staff Scholarship by an authorized administrator of The Research Repository @ WVU. For more information, please contact ian.harmon@mail.wvu.edu. 


\title{
Speaking for "Free": Word of Mouth in Free- and Paid- Product Settings"
}

\author{
[Forthcoming: Journal of Marketing Research]
}

\author{
Samuel D. Bond \\ Scheller College of Business \\ Georgia Institute of Technology \\ 800 W. Peachtree Street \\ Atlanta, GA 30308 \\ Sam.Bond@ scheller.gatech.edu
}

\author{
Stephen X. He \\ College of Business and Economics \\ West Virginia University \\ 1601 University Ave \\ Morgantown, WV 26506 \\ Stephen.He@mail.wvu.edu
}

\author{
Wen Wen \\ McCombs School of Business \\ University of Texas at Austin \\ 2110 Speedway Stop B6500 \\ Austin, TX 78712 \\ Wen.Wen@mccombs.utexas.edu
}

\begin{abstract}
Free-product pricing is increasingly common in the modern marketplace. Our research examines drivers of consumer word of mouth (WOM) in free-product settings, revealing fundamental differences with traditional, paid-product settings. We build and investigate a theoretical model that highlights two unique characteristics of free products (reciprocity motivation and diminished adoption risk) and considers their implications for WOM sharing. Results of a retrospective survey, two controlled experiments, and an analysis of more than 5,000 mobile apps at Google Play and Apple's App Store reveal that consumers are generally more likely to share their opinions of free products than paid products, due to feelings of reciprocity towards the producer. However, this difference is reduced when prior consumer WOM is low in volume and highly disperse, signaling greater adoption risk. Our findings contribute to nascent understanding of free-product marketing, while offering new insights for catalyzing consumer WOM.
\end{abstract}

Key words: word of mouth, social influence, free pricing, online reviews, reciprocity

\footnotetext{
${ }^{*}$ The authors contributed equally, and order is alphabetical. The authors gratefully acknowledge financial support by the Marketing Science Institute and the Sloan Foundation. The authors thank Jack Shen for his outstanding research assistance.
} 
Contemporary marketers are bearing witness to economic and technological transformations that alter traditional notions of value exchange. A prominent example is the dramatic increase in marketing of "free" products (Bryce, Dyer, and Hatch 2011; Lambrecht and Misra 2017), and this trend is especially evident in markets for digital and information goods. The vast majority of mobile apps are available at no cost (Jones 2013), and the standard in many digital categories is a "freemium" pricing model, which charges only for advanced features or services.

Much of the scholarly interest in free-product pricing has focused on marketplace dynamics and strategic considerations underlying the viability of a zero-price model (Foubert and Gijsbrechts 2016; Kumar 2014; Pauwels and Weiss 2008). Other research has documented psychological anomalies that arise when consumers evaluate free products (Nicolau 2012; Palmeira and Srivastava 2013; Shampanier, Mazar, and Ariely 2007). We expand on this trend by considering a previously neglected topic: the unique drivers of consumer word of mouth (WOM) in free-product settings. Our topic is consequential both theoretically and pragmatically, as WOM is often the primary communication channel for firms offering free products (who may lack resources for traditional marketing).

We investigate two related questions. First, are consumers more or less likely to share WOM for free (vs. paid) products? Second, how and why do sharing motivations differ across the two settings? To address these questions, we build a framework offering two distinct pathways by which free pricing has implications for sharing. The first of these pathways involves reciprocity, which compels consumers to "give back" to producers of products received at no monetary cost. The second pathway involves perception of adoption risk, which compels consumers to help 
potential adopters of costly products. To distinguish the two pathways, we incorporate the dynamics of WOM: specifically, we argue that the volume and dispersion of existing WOM should impact perceived risk to potential adopters, but not the desire to reciprocate.

We investigate our framework using multiple methodologies: a retrospective survey, two experiments (involving both hypothetical and actual product experiences), and an empirical examination of archival data. Consistent with our theorizing, findings reveal that consumers of free products are more likely overall to share their opinions than consumers of paid products, but that this enhanced sharing is reduced when existing product WOM is low in volume and highly disperse. Additional process evidence supports the presence of distinct mediating pathways.

By providing evidence of a substantial role for "free" in facilitating WOM, our research contributes to a nascent literature on the viability, implementation, and consequences of zeroprice strategies (Appel, Libai, and Muller 2015; Cheng and Liu 2012; Datta, Foubert, and Heerde 2015; Gill, Sridhar, and Grewal 2017; Oh, Animesh, and Pinsonneault 2016). Our exploration of WOM volume and dispersion supplements recent interest regarding WOM dynamics (Lee, Hosanagar, and Tan 2015; Moe and Schweidel 2012). Finally, we highlight the roles of specific psychological drivers in shaping these dynamics, and how they differ across paid- and freeproduct settings. Supplementing prior literature portraying WOM as self-serving behavior (e.g., De Angelis et al. 2012), our research highlights WOM as a means of serving both producers and other consumers. In this way, we respond to Berger's (2014) call for researchers to “examine factors that encourage people to think more about others."

CONCEPTUAL BACKGROUND

The Pervasive Impact of "Free" 
The provision of products for "free" is a component of various contemporary pricing strategies (tiered pricing, "freemium" pricing, complementary pricing, etc.). For present purposes, we define a "free" product as one that can be acquired without monetary cost, regardless of the underlying pricing model ${ }^{1}$. However, we acknowledge that consumers may construe "free" in various ways that may or may not include non-monetary costs, opportunity costs, potential future costs, etc. (our third study addresses this issue further).

Psychologists have long known that individuals exhibit unique affective, cognitive, and behavioral responses when objects of value are received without expectation of remuneration. Seminal research by Isen and colleagues (e.g., 1978) demonstrated that unexpected gifts lead to more positive mood, enhanced evaluations of unrelated stimuli, more variety-seeking behavior, etc. Within consumer settings, a wide body of evidence reveals substantial and systematic differences in reactions to paid and free products. Merely framing a product as "free" can evoke powerful, positive affective responses that impact subsequent evaluations, and free products are perceived as much more desirable than alternatives of even negligible cost (Shampanier et al. 2007). "Free" offers are less likely than "low-price" or "discounted" offers to negatively impact product evaluations or lower reference prices (Chandran and Morwitz 2006; Palmeira and Srivastava 2013). Free-trial promotions have been shown to enhance sales both by accelerating repeat purchase and by reaching new buyers (Bawa and Shoemaker 2004). In the next sections, we consider an additional, previously neglected benefit of free-pricing, by which customers may be more likely to share product-related WOM.

\footnotetext{
${ }^{1}$ Whether "free" products truly exist in a legal or economic sense is debatable (e.g., Evans 2011), and we remain agnostic on this issue (see the general discussion section). Per our definition, a product is considered "free" as long as the buyer is ignorant or insensitive to monetary costs directly associated with the exchange.
} 


\section{Motivation to Share WOM for Free and Paid Products}

A growing literature has explored the distinct motivations that drive consumer WOM (see Berger 2014 for a review). Much of this literature focuses on impression management: in order to portray a favorable self-image, consumers are more likely to share WOM about interesting products (Berger and Schwartz 2011), WOM that is positive (De Angelis et al. 2012; Wojnicki and Godes 2008), and WOM that is useful to recipients (Moore 2015). Other motivations include emotional regulation (e.g., complaining to reduce negative affect - Hennig-Thurau et al. 2004) and social bonding (e.g., sharing as a means of forming relationships - Chen 2017). Below, we build on these insights to distinguish sharing motivations for free and paid products.

Our framework addresses the following situation: having recently adopted and consumed a free or paid product, a consumer is deciding whether or not to share her opinions with others. We make the simplifying assumption that most users (including the one in question) are at least moderately satisfied with their experience. Although this assumption is restrictive, surveys show the vast majority of online reviews are positive, with average ratings near 4.1/5, 4.0/5, and 7.4/10 for books, restaurants, and video games (Chen and Lurie 2013; Chevalier and Mayzlin 2006; Zhu and Zhang 2010). Moreover, the value of motivating WOM is highest when consumers are satisfied. (In the general discussion, we consider implications of negative experiences.)

Free products are unique from their paid counterparts in a variety of aspects that are likely to impact WOM sharing. In the next sections, we suggest that two of these aspects are especially relevant: 1) heightened reciprocity towards the producer, and 2) the perception of lower product adoption risk. These two aspects form the two distinct pathways of our framework.

\section{Reciprocity: Helping Producers through WOM}


The principle of reciprocity captures the notion that "one good turn deserves another." Abundant, interdisciplinary research demonstrates that this principle is broadly endorsed as a norm for social interaction. Individuals who receive benefits from others show a powerful tendency to engage in reciprocal behavior (Cialdini et al. 1975; Hoppner and Griffith 2011), especially when the benefits are perceived as valuable (Gouldner 1960). In some cases, the need to reciprocate can induce seemingly irrational behavior - for example, complying with requests of greater value than the benefits received (Regan 1971). Downstream effects of reciprocity are observable even in consequential, high-involvement decisions: in one example, commercial bank customers that were given small cash gifts produced larger deposit balances, higher survey response rates, and greater satisfaction (Haisley and Loewenstein 2011).

By definition, consumers of free products receive benefits without providing direct (monetary) compensation to producers of those products. However, it need not be the case that they feel compelled to reciprocate. Modern consumers are often familiar with free or freemium pricing strategies, and they may recognize that firms using such strategies must extract other value to be profitable. Moreover, consumers may assume that they have already "given back" by providing attention, exposing themselves to firm messaging, influencing their peers, etc. (Newman 2015). Compared to monetary payment, however, these means tend to be nebulous, complex, and far removed from the transaction or consumption experience. Thus, we argue that consumers will tend to disregard such means if they are not made explicitly salient. Consistent with this argument, pain-of-payment has been shown to decline dramatically as the payment process becomes less conspicuous (Thomas, Desai, and Seenivasan 2011).

To the extent that consumers of free products perceive that they have received meaningful benefits (i.e., their consumption experience is satisfactory), therefore, they should be motivated 
to seek ways to reciprocate. In theory, reciprocation could take various forms (e.g., allowing use of personal information - Schumann, von Wangenheim, and Groene 2014). However, in many free-product settings (and especially digital categories), one of the most readily available forms is the transmission of positive WOM regarding the product or producer. By sharing their own experience and opinions, satisfied customers not only endorse a product to other potential customers, but also encourage producers to "keep up the good work." In many cases, WOM also provides producers with valuable feedback about product, usage, or consumer characteristics.

The arguments above underlie the first pathway in our framework, illustrated in the top half of Figure 1. Consumers of free products (but not paid products) will be motivated to "return the favor" they have received from producers, and they will share their experience with others as a means of doing so. Our mediational hypothesis is as follows:

H1: Consumers will be more likely to provide WOM for free products than paid products as a result of enhanced reciprocity towards the producer.

[Insert Figure 1 about here]

\section{Adoption Risk: Helping Other Consumers through WOM}

Like their paid counterparts, free products often necessitate a variety of non-monetary costs (inventory, maintenance, disposal, etc.). Nonetheless, both intuition and existing evidence suggest that such costs are not generally salient, and consumers typically perceive lower risk in the decision to adopt a free product (Aydinli, Bertini, and Lambrecht 2014). Along similar lines, 
consumers who have incurred no monetary cost are less likely to experience disappointment or regret, even if their experience is unsatisfactory (Simonson 1992).

One of the primary motivations for sharing product WOM is the desire to help others make informed product decisions (Kronrod and Danziger 2013; Moore 2015). Logically, however, the perceived value of a "more informed decision" depends on the extent to which that decision is consequential (i.e., "Does it matter if they choose incorrectly?"). Thus, the lower risk associated with free products has important consequences for sharing. Even if potential contributors recognize that sharing will benefit others making a product decision, they may discount this benefit because the decision does not seem consequential. This logic forms the basis for the second pathway in our framework, illustrated in the bottom half of Figure 1.

To help identify and distinguish the two contrasting forces: reciprocity (which benefits free products) and adoption risk (which benefits paid products), we next consider WOM dynamicsthe manner in which exposure to existing WOM affects subsequent WOM transmission (Lee et al. 2015; Moe and Schweidel 2012). Given the conspicuous nature of existing WOM, it is reasonable to assume that consumers often use it as an input to their own sharing decision. In particular, we consider existing WOM volume, which captures the magnitude of prior productrelated WOM already available, and existing WOM dispersion, which captures the extent to which reported consumer evaluations of a product differ from one another. Formally, we define existing WOM volume and dispersion (respectively) as the quantity and standard deviation of product ratings assigned by prior reviewers. At most review platforms, both these characteristics are prominently displayed in graphical review summaries.

We argue that both the volume and dispersion of existing WOM provide signals of risk to product adoption. Low (vs. high) volume indicates that less information is available on which to 
base an adoption decision, and high (vs. low) dispersion indicates that the available information is more conflicted; in both cases, the perceived risk of a negative outcome should be enhanced. Importantly, however, these signals are most relevant in the case of paid products, where the "cost" of adoption is more salient (see above). In the case of free products, adoption risk should be perceived as low overall and relatively unaffected by existing WOM.

Combining these ideas completes the second pathway of our framework. Consumers of paid products (but not free products) will recognize an opportunity to help other consumers mitigate adoption risk by providing WOM. However, they will perceive this opportunity to be greatest when existing WOM is insufficient and conflicting. Stated formally:

$\mathrm{H} 2 \mathrm{a}$ : Consumers will be more likely to provide WOM for paid products than free products as a result of increased product adoption risk.

$\mathrm{H} 2 \mathrm{~b}$ : The magnitude of this effect will be strongest when the volume of existing WOM is low and the dispersion of existing WOM is high.

The "net effect" of free- vs. paid-product pricing on WOM depends on the relative strength of the two pathways. Given robust support for powerful and widespread reciprocity effects, it is reasonable to expect that the reciprocity pathway will tend to dominate the risk pathway. At high levels of perceived adoption risk, however, this is less likely to be the case. Stated formally:

H3: Consumers will be more likely to provide WOM for free products than paid products, but the difference will be attenuated when the volume of existing WOM is low and the dispersion of existing WOM is high. 
In the following sections, we describe four studies conducted to investigate our hypotheses. The product category in all studies was web-based or mobile "apps." Beyond the rapid growth of this category in recent years, other properties make it ideal for our investigation: 1) both free and paid pricing strategies are common, 2) app developers are heavily reliant on WOM for marketing communications, and 3) app customers actively spread product-related WOM among their peers, other users, and popular review platforms.

Dependent measures in the four studies include both offline WOM (i.e., recommendation) and online WOM (i.e., review posting). Study 1 investigates the reciprocity pathway by measuring the recalled WOM behavior of actual app users. Study 2 explores both pathways by use of a controlled experiment with a realistic payment and consumption experience. Study 3 replicates and extends these results with a scenario-based survey design. Study 4 examines archival data from real-world app platforms to test our predictions in a natural environment.

\section{STUDY 1: RETROSPECTIVE RECALL - FREE VS. PAID APPS}

Using a retrospective recall design and mobile game apps as the target category, our first study investigated whether free pricing triggers reciprocity and WOM transmission.

\section{Method}

Experimental Procedure. One hundred and ninety-six U.S. residents were recruited from Mechanical Turk and compensated for their time (design and sample considerations were similar to Zhang, Feick, and Mittal 2014). First, participants were asked whether they could identify a 
free game app that they had played recently on a mobile device and been satisfied with overall. Next, they were asked whether they could identify a paid game app meeting the same criteria. Thirty-four participants who could not answer one or both questions were disqualified. The rest were randomly assigned to one of two between-subject conditions (product type: free vs. paid). Depending on condition, participants were asked to name either the free or paid app that they had identified and then complete the dependent measures below. They also completed demographic items and a condition manipulation check, which asked how much money they spent on the app.

WOM Behavior. Using a binary (yes/no) measure, participants reported whether they had "recommended the app to someone else" in the past.

WOM Likelihood. The likelihood and satisfaction measures were adapted from Zhang et al. (2014). Participants rated the likelihood that they would recommend the game app to someone else in the near future, using three, 7-pt items (certain not to recommend / certain to recommend; very unlikely to recommend / very likely to recommend; probably will not recommend / probably will recommend). The three items were averaged. ${ }^{2}$

Satisfaction. The satisfaction measure was included both to ensure that recalled experiences were positive and to control for potential differences in satisfaction. Participants evaluated their experience with the app using two, 7-pt items (very negative / very positive; extremely unsatisfied / extremely satisfied), and these two items were averaged.

Intention to Reciprocate. To capture intention to reciprocate, we adapted two items from Zhang and Epley (2009). Participants rated the extent to which they were "grateful toward the app developers" (1 - not at all grateful, 7 - very grateful) and would "like to thank the developers" (1 - not at all, 7 - a great deal). Responses to the two items were averaged.

\footnotetext{
${ }^{2}$ For participants that reported recommended the app in the past, a value of seven was assigned. All effects reported below remain similar in magnitude and significance when stated values are used instead.
} 
Results

Six participants failed the condition manipulation check, resulting in a usable sample of 156 participants (mean age $=33,44 \%$ female). Satisfying our positivity assumption, participants recalled their experiences with the game apps as positive $(M=6.19, S D=.95)$. Satisfaction was somewhat higher for free than paid apps $(M=6.37$ vs. $6.02 ; F(1,154)=5.51, p<.05)$.

WOM Behavior and Likelihood. We first examined the retrospective measure of WOM behavior. In the free condition, $76 \%$ of participants recalled having recommended the app to someone else, but in the paid condition, only $66 \%$ of participants recalled doing so $\left(\chi^{2}(1)=2.22\right.$, $p<.10)$. We next examined the prospective measure of WOM likelihood. Participants in the free condition reported a significantly greater likelihood of recommending the app to someone else than participants in the paid condition $(M=6.50$ vs. $5.92 ; F(1,154)=7.67, p<.01)$.

Intention to Reciprocate. Participants in the free condition reported significantly greater intention to reciprocate to the app developer than participants in the paid condition $(M=5.42$ vs. $4.98 ; F(1,154)=3.85, p=.05)$. To examine the reciprocity pathway formally, we conducted a bootstrapping mediation analysis with repeated extraction of 5,000 samples (Hayes 2013, Model 4). The model included past WOM transmission behavior as the dependent variable, product type as the independent variable ( 0 - free, 1 - paid $)$, and intention to reciprocate and satisfaction as mediating variables. Results revealed an indirect, negative effect of product type on past WOM transmission behavior through intention to reciprocate $(\mathrm{B}=-.29, \mathrm{SE}=.15,95 \% \mathrm{CI}=[-.66$, -.05]). As predicted by H1, participants were less likely to have transmitted WOM for paid apps due to lower reciprocity intention. Results also revealed a negative, indirect effect of product type through satisfaction $(\mathrm{B}=-.16, \mathrm{SE}=.11,95 \% \mathrm{CI}=[-.46,-.01])$, such that participants were 
less likely to have transmitted WOM for paid apps due to a less positive experience. Using WOM likelihood as the dependent variable, results again revealed a negative indirect effect of product type through intention to reciprocate $(\mathrm{B}=-.08, \mathrm{SE}=.05,95 \% \mathrm{CI}=[-.22,-.01])$.

\section{Discussion}

Study 1 provided initial evidence for our proposed reciprocity pathway. Despite vast heterogeneity in apps and experiences, participants who recalled a free (vs. paid) app were more likely to have recommended that app to others, and were more likely to do so in the future. These differences appeared to be driven (in part) by a greater reciprocity towards the developer,

The retrospective design of Study 1 raises various concerns, including the possibility that pricing affected participants' memory of past WOM behavior but not their actual behavior. Addressing these concerns, our next study provided a "real-time" consumption experience and examined actual decisions to share WOM. The study also investigated the second pathway in our model, by which free pricing may not increase WOM due to perceptions of lower adoption risk.

\section{STUDY 2: EXPERIMENT - DECISION TO SHARE WOM FOR A WEB APP}

The focal product of our second study was a web-based, visa photo editing app created specifically for the study (see Web Appendix A). The inclusion of a "real" product ensured that

participants could actually experience the product before deciding whether to post a review, and it also allowed us to manipulate product type in a realistic manner (see below).

\section{Method}


Experimental Procedure. Three hundred and eighty-eight U.S. residents were recruited from Mechanical Turk and compensated for their time. Participants were randomly assigned to one of eight conditions in a 2 (product type: free vs. paid) $\times 2$ (WOM volume: low vs. high) $\times 2$ (WOM dispersion: low vs. high) between-subjects design.

The cover story informed participants that they would be using two different apps-one free and one paid—in a random order ${ }^{3}$. Participants were asked to imagine that they were planning a business trip to China with a colleague, and that their colleague needed a visa photo meeting the requirements of the Chinese Embassy. The participant had volunteered to help create such a photo, using a web-based photo editing app provided by the experimenters.

To manipulate product type, participants learned that the photo app was either free of charge or that it cost 50 cents per photo created. To ensure that participants in the paid condition actually "experienced" the act of paying (Rick, Cryder, and Loewenstein 2008), they were told that 50 cents would be deducted from their study compensation (\$2), and they were reminded of this charge immediately before accessing the app. The app was located on a separate website and accessed by clicking a hyperlink. After undergoing a brief training session, participants went through a step-by-step process to create the photo for their colleague.

Immediately they finished using the photo app, participants were shown a message "from the app developers," requesting that they post a review of their experience on a popular review forum. The following screen presented a summary of existing reviews at the forum, in which the volume and dispersion manipulations were embedded (see Figure 2). Participants in the low (high) volume condition saw that the app had received 47 (987) reviews, and the text noted that "not many (many) people have posted reviews." Dispersion was manipulated by two graphical

\footnotetext{
${ }^{3}$ Providing this information ensured that both free and paid conditions would expect the same total compensation. At the end of the study, participants learned that there was no second app to evaluate.
} 
ratings distributions (He and Bond 2015). The means of the two distributions were identical (four stars out of five), but their standard deviations differed substantially ( $S D=.71$ vs. 1.49 for lowand high-dispersion, respectively). Accompanying text noted that the app had "received very similar (diverse) reviews from pervious users: the ratings given by most users did not differ very much (some users gave very high ratings, and other users gave very low ratings)." The manipulations were validated through a separate pretest, described in Web Appendix B.

[Insert Figure 2 about here]

Participants stated their decision whether to post a review for the photo app, and then responded to process measures described below. Finally, they completed a demographic questionnaire including measures for age, gender, frequency of review posting, prior use of similar apps, and attention checks (Oppenheimer, Meyvis, and Davidenko 2009).

Intention to Reciprocate. This measure consisted of two items identical to those in Study 1.

Perceived Adoption Risk. Participants rated their agreement with two statements, using 5-pt scales (1 - strongly disagree, 5 - strongly agree): 1) "Potential users will be uncertain about the usefulness of the app"; 2) "For potential users, whether or not to adopt the app is a difficult decision." Responses to the two items were averaged.

Attitude toward the App. To ensure that participants held positive and similar opinions of the app, they completed three 7-pt items (1 - not at all good, 7 - very good; 1 - not at all effective, 7 - very effective; 1 - not at all useful, 7 - very useful). Responses were averaged.

\section{Results}

Thirty-four participants either failed to open the web-based app, did not complete the study, missed more than one attention check, or incorrectly recalled the product type; their exclusion 
left a sample of 354 participants (mean age $=37,47 \%$ female). Fewer than $5 \%$ reported prior use of similar apps (analyses below include these participants, but results are similar when they are excluded.) Attitude ratings indicated that participants were satisfied with the app overall $(M=$ $5.65, S D=1.07)$. Forty-eight percent of participants indicated that they "never" or "rarely" posted consumer reviews, consistent with findings of other research (Smith and Anderson 2016).

Posting Decision. Figure 3 illustrates the proportion of participants in each condition who agreed to post a review. Decision to post was examined via a binary logistic regression including product type, WOM volume, WOM dispersion, and their interactions, controlling for frequency of review posting ${ }^{4}$. Analyses revealed a main effect of product type $\left(\chi^{2}(1)=8.79, p<.01\right)$, such that a larger proportion of participants chose to post a review when the app was free than paid $(52 \% \text { vs. } 33 \%)^{5}$. Most important, and in line with predictions, analyses also revealed a significant product type $\times$ volume $\times$ dispersion interaction effect $\left(\chi^{2}(1)=3.86, p<.05\right)$.

To explore the interaction, we conducted separate follow-up contrasts at each level of existing WOM volume. When volume was high, results revealed only a main effect of product type $(Z=2.94, p<.01)$, such that posting was more likely when the app was free rather than paid. When existing volume was low, however, results revealed a significant product type $\times$ dispersion interaction $(Z=2.30, p<.05)$ whose pattern was consistent with hypotheses. Specifically, when dispersion was also low, posting was more likely when the app was free than paid (54\% vs. $21 \% ; Z=3.24, p<.01)$, but when dispersion was high, the difference disappeared $(48 \%$ vs. $50 \% ; Z=-.14, p>.30)$.

\footnotetext{
${ }^{4}$ When past posting frequency is not controlled for, the product type $\times$ volume $\times$ dispersion interaction becomes marginal $(p<.10)$. The mediation effect of intention to reciprocate $(\mathrm{B}=-.41, \mathrm{SE}=.23,95 \% \mathrm{CI}=[-.93,-.01])$ and the moderated mediation effect of perceived adoption risk $(\mathrm{B}=-.36, \mathrm{SE}=.21,95 \% \mathrm{CI}=[-.91,-.06])$ are supported. ${ }^{5}$ In an exploratory analysis, we examined the text reviews written by the participants who chose to post, using the Linguistic Inquiry and Word Count (LIWC; Pennebaker et al. 2015), Among notable findings, reviews in the free condition contained marginally more positive emotional words than those in the paid condition $(M=12.10$ vs. 9.57; $F(1,144)=3.15, p=.08)$, and indicated directionally greater effort $(M=26.72$ vs. $22.82 ; F(1,144)=1.80, p=.18)$.
} 
[Insert Figure 3 about here]

Intention to Reciprocate. An ANOVA including the three treatment variables and their interactions revealed a significant main effect of product type $(F(1,346)=24.30, p<.001)$, such that intention to reciprocate was higher when the app was free rather than paid ( $M=4.86$ vs. $4.02 ; F(1,346)=24.30, p<.001)$. To investigate the reciprocity pathway formally, we conducted a mediation analysis similar to that described in Study 1. Consistent with hypotheses, results revealed an indirect, negative effect of product type on posting choice through the intention to reciprocate $(\mathrm{B}=-.34, \mathrm{SE}=.18,95 \% \mathrm{CI}=[-.80,-.07])$. Results did not support a mediating role for attitude towards the app $(\mathrm{B}=-.15, \mathrm{SE}=.13,95 \% \mathrm{CI}=[-.44, .07])$.

Perceived Adoption Risk. According to the second pathway of our framework, charging for a product increases the perceived risk of adoption when existing WOM signals uncertainty. ANOVA revealed a marginal main effect of product type $(F(1,346)=3.23, p=.07)$, a significant main effect of volume $(F(1,346)=5.23, p<.05)$, and a directional effect of dispersion $(F(1,346)=1.26, p=.26)$. Most important, results revealed a significant product type $\times$ volume $\times$ dispersion interaction $(F(1,346)=8.31, p<.01)$. Consistent with hypotheses, the effect of product type on perceived risk was most pronounced at a combination of low volume and high dispersion $\left(M_{\text {free }}=2.74\right.$ vs. $\left.M_{\text {paid }}=3.21 ; F(1,346)=6.41, p<.05\right)$.

To explore the pathway formally, we conducted a moderated mediation analysis using bootstrapping with repeated extraction of 5,000 samples (Hayes 2013, Model 11). The analysis included product type as the independent variable ( 0 - free, 1 - paid), perceived adoption risk as the mediator, volume ( 0 - low, 1 - high $)$ and dispersion ( 0 - low, 1 - high $)$ as moderators, and posting choice as the dependent variable, controlling for frequency of review posting. As predicted, results revealed an indirect, positive effect of product type on posting choice through 
perceived adoption risk, moderated by the volume $\times$ dispersion interaction $(\mathrm{B}=-.28, \mathrm{SE}=.19$, $95 \% \mathrm{CI}=[-.79,-.01])$. Follow-up analyses indicated that the indirect effect was reliable at a combination of low volume and high dispersion $(\mathrm{B}=.12, \mathrm{SE}=.09,95 \% \mathrm{CI}=[.01, .36])$, but not at any of the other volume $\times$ dispersion conditions ( $\mathrm{Bs}=-.04$ to .09 ; all 95\% CIs include zero).

\section{Discussion}

Using an experimental design and a realistic product setting, Study 2 supported our claim that free pricing has nuanced implications for WOM, due to its distinct impact on reciprocity and perceptions of adoption risk. Reflecting the reciprocity route, participants were more likely overall to post a review when the product was free. Reflecting the perceived risk route, this effect was virtually eliminated when prior WOM was limited in volume and highly disperse.

Participants in the study did not view information about prior WOM until they had already experienced the app. However, prior WOM is often encountered prior to a product decision (and may even influence that decision). Therefore, we conducted a follow-up study, described in Web Appendix C: participants chose between two different apps based on prior WOM distributions, experienced the app, and decided whether to post. Findings were consistent with those of the main study, though evidence for the mediating pathways was only suggestive. In addition, an

exploratory text analysis of open-ended responses yielded suggestive evidence that reciprocity motivation was stronger for participants in the free condition than the paid condition.

STUDY 3: EXPERIMENT - INTENTION TO SHARE WOM FOR A MOBILE APP 
Our third study was designed to replicate Study 2 in a more controlled setting, while extending the investigation to other forms of free-product pricing. "Free" products often come with qualifications that create value for providers (e.g., advertising, time or usage limitations, paid upgrades or accessories). The more salient such qualifications, the more likely consumers should be to view the exchange as costly. In terms of our two pathways, as a result, qualifications should reduce motivation to share WOM as a means of reciprocation, but increase motivation to share WOM as a means of reducing others' adoption risk. Therefore, we examined three pricing models common in the app market, which differ in the extent to which qualifications are salient: free, free $+a d s$, and paid.

Study 3 was entirely scenario-based, ensuring that all participants shared an identical consumption "experience." Participants were told that after a positive app experience, they had been asked by the developers to provide a review. Next, they saw a summary of existing reviews and reported their willingness to provide their own. Stimuli are presented in Web Appendix D.

\section{Method}

Experimental Procedure. Seven hundred and seventy-eight U.S. residents were recruited from Mechanical Turk and compensated for their time. Participants were randomly assigned to one of twelve conditions in a 3 (product type: free vs. free+ads vs. paid) $\times 2$ (WOM volume: low vs. high) $\times 2$ (WOM dispersion: low vs. high) between-subjects design. The cover story asked participants to imagine that they recently downloaded a mobile app, "HealthyU," which helps users monitor their diet and exercise while maintaining a healthy lifestyle (the description was adapted from Batch et al. 2014). All participants were told that they had downloaded a "basic" version of the app, which could be upgraded to an "advanced" version for a fee. To manipulate 
product type, participants were told that the basic version was either free of charge and ad-free (free), free of charge with sponsored ads (free+ads), or \$2.99 and ad-free (paid).

The scenario explained that after two months of largely positive experiences with the app (see Web Appendix D), participants received a "pop-up message” from the developers, requesting that they post a review. Participants then saw a summary of existing reviews, in which the four volume $\times$ dispersion conditions were represented by graphical distributions identical to those in Study 2. Participants reported their intention to post a review and responded to process measures described below. At the end of the study, they rated the realism of the scenario ( $1-$ not realistic at all, 7 - extremely realistic), and they completed attention checks and demographic questions similar to those in Study 2.

Intention to Post. Participants rated both how likely (1 - not very likely, 7 - very likely) and how motivated ( 1 - not very motivated, 7 - very motivated) they would be to "post a star rating and a text review" at the review forum. Responses to the items were averaged.

Intention to Reciprocate, Perceived Adoption Risk, Attitude toward the App. Measures were identical to those in Study 2.

Self-serving Motivation. A plausible alternative to our proposed reciprocity mechanism is that individuals spread WOM for free products to help ensure that the products remain available, continue to be updated, etc. To captured "self-serving" motivation, we included two 5-pt items, measuring the extent to which it was in participants' best interest to help the developers, and the extent to which they would do so "to benefit myself." Responses to the items were averaged.

Chance of Survival. On the one hand, consumers may feel that the effort of sharing WOM is only worthwhile for products that are likely to "survive" in the marketplace. On the other hand, consumers may see greater value in sharing WOM when they perceive survival to be in jeopardy. 
To explore both possibilities, we asked participants how likely it was that the app would "be successful for a long period of time" (1 - not likely at all, 5 - extremely likely).

\section{Results}

Ninety-five participants either did not complete the study, failed more than one attention check, or incorrectly recalled their product type condition; their exclusion left a sample of 683 participants (mean age $=35,53 \%$ female). On average, participants deemed the scenario realistic $(M=5.73, S D=1.21)$ and had a positive attitude toward the app $(M=5.64, S D=1.02)$. Fiftyeight percent of participants indicated that they had used a similar app in the past ${ }^{6}$.

Intention to Post. Figure 4 depicts mean intention to post by condition. As predicted, ANOVA revealed a significant main effect of product type $(F(2,671)=16.53, p<.001)$. Participants were more willing to post a review when the app was free than paid ( $M=4.77$ vs. $3.82 ; F(1,671)=28.83, p<.001)$. Intention to post in the new, free+ads condition $(M=4.01)$ was significantly lower than that in the free condition $(F(1,671)=19.59, p<.001)$, but only directionally higher than that in the paid condition $(F(1,671)=1.06, p=.30)$.

As predicted, analyses also revealed a significant product type $\times$ volume $\times$ dispersion interaction $(F(2,671)=3.07, p<.05)$. At high existing volume, results indicated only a main effect of product type $(F(2,671)=9.59, p<.001)$, such that intention was higher when the app was free than when it was free with ads or paid. At low existing volume, however, results revealed a product type $\times$ dispersion interaction $(F(2,671)=3.37, p<.05)$; follow-up comparisons revealed that product type only affected intention when dispersion was also low.

[Insert Figure 4 about here]

\footnotetext{
${ }^{6}$ When past usage is controlled for, results are similar to those reported below (see Web Appendix E).
} 
Intention to Reciprocate. An ANOVA including the three treatment variables and their interactions revealed a main effect of product type $(F(2,671)=17.82, p<.001)$, such that intention to reciprocate was higher in the free condition than the free+ads condition $(M=5.50$ vs. $4.97 ; F(1,671)=16.71, p<.001)$ or the paid condition $(M=4.73 ; F(1,671)=33.61, p$ $<.001)$. To investigate the reciprocity pathway formally, we conducted a mediation analysis similar to that of Study 2, including only the free and paid conditions. Consistent with hypotheses, results revealed an indirect, negative effect of product type on intention to post through intention to reciprocate $(\mathrm{B}=-.87, \mathrm{SE}=.21,95 \% \mathrm{CI}=[-1.28,-.46])$.

To address the potential roles of attitude towards the app, self-serving motivation, and chance of survival, we added these variables to the mediation model. Results did not support a mediating role for attitude towards the app or self-serving motivation (95\% CIs included zero). However, results did reveal a mediating role for chance of survival $(\mathrm{B}=-.18, \mathrm{SE}=.09,95 \% \mathrm{CI}$ $=[-.41,-.04])$, suggesting that participants were more willing to post reviews for free apps due to the perception that they were more likely to survive. However, results continued to reveal a mediating role for intention to reciprocate $(\mathrm{B}=-.69, \mathrm{SE}=.18,95 \% \mathrm{CI}=[-1.07,-.36])$.

Perceived Adoption Risk. ANOVA revealed significant main effects of product type ( $F(2$, $671)=4.14, p<.05)$, volume $(F(1,671)=16.51, p<.001)$, and dispersion $(F(1,671)=19.52, p$ $<.001)$. Most important, results also revealed a marginal product type $\times$ volume $\times$ dispersion interaction effect $(F(2,671)=2.48, p=.08)$, whose pattern was consistent with predictions. Under a combination of low volume and high dispersion, perceived adoption risk was lower when the app was free than when it was free with ads or paid $(M=2.83$ vs. $3.37 ; F(1,671)=$ $10.94, p<.001$; vs. $3.44 ; F(1,671)=14.20, p<.001)$. For all other combinations of volume and dispersion, perceived risk did not significantly differ by product type $(p>.30)$. 
To investigate the adoption risk pathway formally, we conducted a moderated mediation analysis similar to that in Study 2. Consistent with hypotheses, results supported an indirect, positive effect of product type on intention to post through perceived adoption risk, moderated by the volume $\times$ dispersion interaction $(\mathrm{B}=-.16, \mathrm{SE}=.11,95 \% \mathrm{CI}=[-.48,-.01])$. The indirect effect was reliable at a combination of low volume and high dispersion $(\mathrm{B}=.13, \mathrm{SE}=.08,95 \%$ $\mathrm{CI}=[.01, .32]$ ), but not at any of the other volume $\times$ dispersion conditions (all CIs contain zero).

\section{Discussion}

Extending Studies 1-2, our third study provided convergent evidence for the two pathways in our framework. Supporting the reciprocity pathway, sharing intention was stronger when a product was "free" than when the producer was being "paid," either directly or indirectly. Supporting the risk pathway, however, free pricing also activated an opposing process when existing product WOM signaled high levels of adoption risk.

Results for the new, free+ads condition were largely similar to those in the paid condition. This similarity supports the notion that imposing salient noneconomic costs on an ostensibly "free" product can reduce motivation to share WOM as a means of reciprocating to the developer, but can increase motivation to do so as a means of helping others limit adoption risk.

STUDY 4: FIELD DATA - ACTUAL WOM SHARING FOR MOBILE APPS

\section{Research Setting and Methodology}

Although the findings of the first three studies provide consistent support for our framework, their interpretation is hindered by necessary design limitations. For example, Study 1 relied heavily on participants' memory, and studies 2-3 required participants to "experience" a product 
that they had not actually sought or chosen; "payment" in paid conditions was either facilitated by study compensation (Study 2) or hypothetical (Study 3). To address these limitations, our final study involved an archival analysis of real-world data from the two leading mobile app platforms: Google's Google Play store and Apple's App Store. This setting provides an externally valid and meaningful context for testing our framework. In 2016, the two platforms were responsible for 100 billion downloads and generated more than $\$ 35$ billion in revenue. Pricing on the platforms varies considerably, with a large proportion of developers utilizing freepricing models. Moreover, both platforms enable users to easily view prior app reviews or post their own review. The accumulation of reviews is critical to developers, as reviews not only play a direct role in adoption decisions, but also affect the visibility of apps on the platforms.

To explore how product type and existing WOM influence subsequent review posting, we implemented a difference-in-differences estimation approach (Chevalier and Mayzlin 2006; Zhu and Zhang 2010; Sun 2012). We restricted our focus to apps available at both platforms. By focusing on differences between the two platforms for the same apps, we could largely eliminate unobserved heterogeneity across apps that may affect pricing or sharing. By comparing this difference at two points in time, we could also control for platform-specific characteristics.

\section{Model Specification}

We define NewReviews ${ }^{K}$ it as the total number of reviews posted at time $t$ for a specific app $i$ listed on platform $\mathrm{K}$ (where $\mathrm{K}$ is either Google Play or the App Store). NewReviews ${ }^{K}$ it is specified as a function of the following variables. First, to represent whether app $i$ is free at time $t$, we include the dummy variable Free (equal to 1 if free and 0 otherwise). Second, the existing volume and dispersion of reviews for app $i$ at time $t$ are measured by two dummy variables: Low 
Volume ( $L V$, equal to 1 if app $i$ 's review volume is low and 0 otherwise), and High Dispersion ( $H D$, equal to 1 if app $i$ 's review dispersion is high and 0 otherwise). We also include the interactions of $L V, H D$, and $\mathrm{Free}^{7}$, resulting in the following specification:

$$
\begin{aligned}
& \text { NewReviews }^{K}{ }_{\mathrm{it}}=\beta_{1} \text { Free }^{K}{ }_{\mathrm{it}}+\beta_{2} L V^{\mathrm{it}_{\mathrm{t}}}+\beta_{3} H D^{K}{ }_{\mathrm{it}}+\beta_{4} \text { Free }_{\mathrm{it}}{ }_{\mathrm{it}} * L V^{K}{ }_{\mathrm{it}}+\beta_{5} F_{r e e}{ }_{\mathrm{it}} * \\
& H D^{K}{ }_{\mathrm{it}}+\beta_{6} L V^{K}{ }_{\mathrm{it}} * H D^{K_{\mathrm{it}}}+\beta_{7} \text { Free }^{K}{ }_{\mathrm{it}} * L V^{\mathrm{it}_{\mathrm{t}}} * H D^{K}{ }_{\mathrm{it}}+\text { Controls }_{\mathrm{it}}+v_{\mathrm{i}}+\mu^{K_{\mathrm{i}}}+\varepsilon_{\mathrm{it}}
\end{aligned}
$$

The variable $v_{\mathrm{i}}$ captures app-level fixed effects, and the variable $\mu^{K}{ }_{\mathrm{i}}$ captures platform-level fixed effects. An important concern is that free apps might reasonably be expected to generate greater demand, which would naturally result in more reviews. Therefore, we include in Controls ${ }_{\text {it }}$ two ranking dummy variables: OverallTop500 indicates whether app $i$ was ranked among the top 500 apps for platform $K$ at time $t$, and CategoryTop500 indicates whether app $i$ was ranked among the top 500 apps in its category for platform $K$ at time $t^{8}$ Another concern is that paid apps might reasonably be expected to be higher in quality, which may itself impact the accumulation of reviews. Therefore, we include in Controls $^{K}$ it the variable Rating, indicating the average customer rating of app $i$ in platform $K$ at time $t$.

Our framework predicts that changing from a paid app to a free app will have a positive effect on review posting, but that this effect will be attenuated when existing WOM provides a strong signal of user risk-i.e., when volume is low and dispersion is high. Therefore, we are most interested in the coefficients $\beta_{1}$ and $\beta_{7}$. An implicit assumption is that the price and existing WOM of an app at one platform have little influence on review sharing for the same app at the other platform. We believe this to be a fair assumption (as the two platforms are incompatible), and our approach is consistent with research in similar settings (e.g., Zhu and Zhang 2010).

\footnotetext{
${ }^{7}$ Given that our specification includes two- and three-way interaction terms, use of dummy measures for volume and dispersion greatly alleviates interpretation. As a robustness check, we employ continuous measures (see below) ${ }^{8}$ The primary determinant of an app's ranking is number of downloads. We were unable to utilize exact ranks, as this information is unavailable for apps ranked below 500 .
} 
To remove app-specific effects $v_{\mathrm{i}}$, we take the difference in NewReviews $\mathrm{sit}_{\mathrm{i}}$ between Google Play (denoted by the superscript $G$ ) and the App Store (denoted $A$ ), resulting in the following:

$\Delta$ NewReviews $_{\mathrm{it}}=\beta_{1} \Delta$ Free $_{\mathrm{it}}+\beta_{2} \Delta L V_{\mathrm{it}}+\beta_{3} \Delta H D_{\mathrm{it}}+\beta_{4} \Delta$ Free $_{\mathrm{it}} * L V_{\mathrm{it}}+\beta_{5} \Delta$ Free $_{\mathrm{it}}$

* $H D_{\mathrm{it}}+\beta_{6} \Delta L V_{\mathrm{it}} * H D_{\mathrm{it}}+\beta_{7} \Delta$ Fre e $_{\mathrm{it}} * L V_{\mathrm{it}} * H D_{\mathrm{it}}+\Delta$ Controls $_{\mathrm{it}}+\left(\mu_{\mathrm{i}}-\mu^{\mathrm{A}} \mathrm{i}\right)+\varepsilon_{\mathrm{it}}$,

where $\Delta$ NewReviews $_{\mathrm{it}}=$ NewReviews $_{\mathrm{it}}-$ NewReviews $^{A}{ }_{\mathrm{it}}, \Delta$ Free $_{\mathrm{it}}=$ Free $_{\mathrm{it}}-$ Free $_{\mathrm{it}}{ }_{\mathrm{it}}, \Delta L V_{\mathrm{it}}=L V^{G}{ }_{\mathrm{it}}$ $-L V^{A}{ }_{\mathrm{it}}, \Delta H D_{\mathrm{it}}=H D^{G}{ }_{\mathrm{it}}-H D_{\mathrm{it}}^{A}$, etc.

To remove the platform-specific effect $\left(\mu_{i}{ }_{i}-\mu_{i}^{A}\right)$, we next take the difference in equation (2) between time $t$ and time $t+1$. The result is the main specification for our analyses:

$$
\begin{gathered}
\Delta \Delta \text { NewReviews }_{\mathrm{it}}=\beta_{1} \Delta \Delta F r e e_{\mathrm{it}}+\beta_{2} \Delta \Delta L V_{\mathrm{it}}+\beta_{3} \Delta \Delta H D_{\mathrm{it}}+\beta_{4} \Delta \Delta F r e e_{\mathrm{it}} * L V_{\mathrm{it}}+\beta_{5} \\
\Delta \Delta \text { Free }_{\mathrm{it}} * H D_{\mathrm{it}}+\beta_{6} \Delta \Delta L V_{\mathrm{it}} * H D_{\mathrm{it}}+\beta_{7} \Delta \Delta F r e e_{\mathrm{it}} * L V_{\mathrm{it}} * H D_{\mathrm{it}}+\Delta \Delta \text { Controls }_{\mathrm{it}}+\varepsilon_{\mathrm{it}} .
\end{gathered}
$$

\section{Data and Summary Statistics}

We randomly selected 6,300 apps available at both Google Play and the App Store between September 2014 and March 2015. Of these 6,300 apps, 5,954 had received at least one review by September 1, 2014. We next removed 289 "corporate" apps intended to support offline businesses (banking, airline, hotel, etc.), as motivations in that category are likely to be unique. Our final sample consisted of 5,665 apps and included prices, review distributions, and rankings at both platforms for the September 2014 and March 2015 periods.

Table 1 presents the mean and standard deviation of key variables. Apps at Google Play received substantially more reviews than those at the App Store, which likely reflects the larger Android user base during the sample periods. The majority of apps at both platforms were free (68\% at Google Play vs. 64\% at the App Store). Apps at Google Play were rated slightly higher than those at the App store, and their ratings were somewhat more disperse.

[Insert Table 1 about here]

As model-free evidence, Figure 5 presents the number of new reviews separately for free and paid apps and for different distributions of existing WOM. Providing initial support for our 
claims, free apps received more new reviews than paid apps when the existing volume was high (regardless of dispersion), or when existing reviews were homogeneous (regardless of volume). However, the difference disappeared for apps with a limited number of disperse reviews.

[Insert Figure 5 about here]

\section{Results}

Table 2 presents baseline regression results for specification (3). Because the number of new reviews (NewReviews $s_{\mathrm{it}}$ ) was highly skewed, we applied a log-transformation to this variable. The low volume $(L V)$ and high dispersion $(H D)$ categories were assigned by median split.

Column (1) in Table 2 contains no interaction terms or control variables, and column (2) adds controls. Not surprisingly, both OverallTop500 and CategoryTop500 were positively correlated with number of new reviews (i.e., more popular apps attract more reviews). More important, the coefficient of $\triangle \Delta F r e e$ is significantly positive for both models. The magnitude of the effect in column (2) can be illustrated as follows: Were a paid app that normally receives 100 monthly reviews to become free, it would be expected to receive 222 monthly reviews.

Column (3) adds interaction terms to the specification without controls, and column (4) adds back controls. Examination of column (4) reveals evidence for both key predictions. The coefficient of $\triangle \triangle F r e e$ remains significant and positive, suggesting that motivation to post WOM for free products is generally greater than that for paid products. The coefficient of $\triangle \Delta F r e e^{*} L V^{*} H D$ is significant and negative, suggesting that the positive effects of free pricing on posting are attenuated when existing WOM implies high adoption risk. ${ }^{9}$

\footnotetext{
${ }^{9}$ A potential concern is the influence of "robot-generated" reviews in this setting. We acknowledge the concern but do not deem it a severe threat to our interpretation, as it cannot easily explain the observed difference between free and paid apps or the observed interaction effects. Moreover, the DiD estimation approach removed app-specific effects (allaying the concern that some apps but not others contained "robot" reviews).
} 


\section{[Insert Table 2 about here]}

Table 3 presents marginal effects of changing from "paid" to "free" on new monthly posts. The marginal effect is smallest in the low-volume, high-dispersion group $(L V=1, H D=1)$, and the marginal effect in this group is significantly smaller than that in the other three groups. To illustrate, assume that a paid app which normally receives 100 monthly reviews changes to free. If the app has a large volume of existing reviews or those reviews are homogenous, then our estimates predict 228-240 new monthly reviews. On the other hand, if the app has accumulated a low volume of heterogeneous reviews, then our estimates predict only 194 new monthly reviews. [Insert Table 3 about here]

In a series of robustness checks (see Web Appendix F), we did the following: 1) employed a continuous measure for existing volume and dispersion, 2) restricted the analysis to the subsample of apps with high average rating (at least four out of five), and 3) implemented a cross-sectional analysis. Results of all checks were qualitatively similar to the baseline results.

\section{Discussion}

The main findings of Study 4 were largely consistent with our predictions and the findings of Studies 1-3. In particular, free pricing appeared to stimulate WOM sharing (in the form of reviews), but this stimulating effect was reduced when existing WOM signaled high adoption risk. Although the "real-world" setting precluded direct measure of underlying psychological processes, it provided an externally valid context that complemented the earlier studies, while informing understanding of how mobile app pricing influences actual customer WOM. 
Despite the recent proliferation of "freemium" and related business models, extant research offers surprisingly few insights regarding the implications of free-product settings for WOM. Addressing this gap, our theoretical framework highlights two characteristics that distinguish free products from their paid counterparts—reciprocity and lower adoption risk—and argues that these bear distinct implications for sharing. On the one hand, reciprocity facilitates motivational effects oriented towards producers, as consumers of free products seek to "give back in return" for benefits provided at no (monetary) cost. In our studies, this pathway played out in a positive, large, and consistent effect of free pricing on willingness to provide WOM, mediated by intentions to reciprocate. On the other hand, adoption risk facilitates motivational effects oriented toward other potential adopters, as consumers of paid products seek to help others with their decisions. In our studies, this pathway played out in a negative, moderate, and consistent effect of zero-pricing on willingness to provide WOM, mediated by perceptions of adoption risk. Consistent with our argument for distinct pathways, the second pathway (but not the first) was sensitive to features of existing WOM that signal adoption risk.

Although WOM is typically portrayed as a self-serving behavior, scholars are increasingly aware that this portrayal is incomplete, and have emphasized the need to examine more altruistic motivations (Berger 2014). Addressing this issue, our findings suggest that product-related WOM can be influenced by the motivation to help producers and other consumers. However, we acknowledge that these motivations might also be self-serving: for example, "reciprocating" app developers via positive WOM might also help customers avoid feeling guilty, and "providing useful information" to potential adopters might also enhance status or reputation. Nonetheless, our focus on other-oriented motivations provides a useful supplement to other approaches. 
Our theorizing required the assumption of a satisfactory consumption experience. This assumption was based on both pragmatic concerns (keeping the theory tractable) and practical concerns (producers stand the most to gain from positive WOM). Were this assumption to be dropped, it is reasonable to expect that dissatisfaction would interfere with the proposed reciprocity pathway; i.e., the desire to "give back" should diminish when a product does not perform as expected. However, the implications of dissatisfaction for the adoption risk pathway are less clear, and we encourage additional exploration. Similarly, our theorizing assumes minimal discrepancy between one's own experience and the consensus of prior WOM. The implications of a discrepancy for sharing are nonobvious and worthy of investigation.

Participants in our two experiments engaged in "one-shot transactions" with the seller, limiting any opportunity for learning or relationship formation. However, repeated interactions might be expected to alter the nature of the relationship in ways that would impact our findings. In particular, repeated interactions are likely to influence the extent of reciprocity motivation (and its ramifications for WOM). Research addressing this possibility would be fruitful.

Intuitively, it is plausible that a large enough volume of existing WOM would discourage consumers from providing their own, even in free-product settings. This intuition is consistent with the "crowding-out" effect observed in charitable donation contexts (Abrams and Schitz 1978). However, our data do not show evidence of such an effect, and our theory does not predict it. In contrast to charitable contexts, where the goal is to help a target in need or contribute to the greater good, our reciprocity mechanism involves a goal of paying back a personal debt to the provider of a free product. To the extent that a personal debt cannot be paid by others, reciprocity cannot be "crowded out," and consumers of free products should feel compelled to share WOM even when voluminous prior WOM is available. 
In practice, free-product pricing underlies a wide variety of pricing strategies and revenue models (penetration pricing, freemium and tiered models, complementary pricing, etc.). Considering the implications of each is outside the scope of our research, but our findings offer initial insights. On the one hand, results were largely consistent for the "free" conditions of Study 2 (in which no explanation was provided), Study 3 (in which participants were explicitly informed of a freemium pricing model), and Study 4 (which contained a diverse range of "free" apps). On the other hand, the positive impact of free pricing on reciprocity diminished in the "free+ads" condition of Study 3, where the presence of a nonmonetary cost was salient. Thus, consumer inferences regarding the "true cost" of free pricing seem to play an important role in psychological and behavioral responses. We encourage further exploration of those inferences.

Among myriad factors to consider when determining pricing strategy, one factor that may be overlooked is the effect of price on customers" desire to "spread the word" via WOM. Our findings suggest that zero-cost pricing is generally facilitative to WOM. Although it is unrealistic to base pricing decisions on this benefit alone, our findings are clearly relevant to firms that are actively considering a free-pricing strategy, and also to market contexts where rapid awareness or network effects are important - in online retail, the accumulation of online WOM can increase adoption rates by as much as $270 \%$ (Askalidis and Malthouse 2016). Based on a simplified profit-maximization model and the effect sizes observed in Study 4, the free-to-paid conversion rate required for a "freemium" strategy to outperform a "paid" strategy is halved when the beneficial effects of free pricing on WOM are accounted for.

Although our theorizing is predicated on the existence of "free" products, the concept itself is debatable in both legal and economic senses (Evans 2011; Newman 2015). We acknowledge that given reasonable assumptions, a truly "free" product may not exist—or not be sustainable in 
the marketplace. Nonetheless, many marketers label their products as "free," and a long line of consumer research indicates that "free" labels induce consumers to think, feel, and act in systematically different ways (Shampanier et al. 2007). That line of research typically considers a "free" product to be one acquired without monetary cost, and a general finding is that buyers are remarkably insensitive to non-monetary costs. We adopt a similar definition, and our framework applies to products that are perceived to be free, whether or not that is truly the case.

Our findings reveal important differences in consumer motivation between free- and paidproduct settings, driven by differences in perceived obligations to producers and to other consumers. Given that reciprocity towards the producer is an important catalyst of WOM in freeproduct settings, marketers may find it worthwhile to embed reciprocity cues overtly in their communications. For example, post-consumption messaging often encourages customers to "spread the word" "or tell your friends about us"; within such messaging, marketers might not only remind customers of their satisfactory experience, but also of specific steps taken by the firm to bring that experience about. Similarly, marketers in paid product settings may find it worthwhile to encourage customers to explicitly contemplate the value of their WOM to others. For example, review solicitations might specifically itemize the diverse benefits of product reviews to other shoppers ("save them time," "help them choose," "save them money," etc.) Moreover, our findings indicate that willingness to share paid-product WOM increases when existing WOM is low in volume and heterogeneous. For review solicitations, a straightforward implication is to emphasize that the quantity of existing reviews is lacking, or that previous customers have diverged in their opinions (or both). As a result of this emphasis, potential contributors will be directed to specific informational cues that motivate sharing. 


\section{REFERENCES}

Abrams, Burton A. and Mark D. Schitz (1978), "The 'Crowding-out' Effect of Governmental Transfers on Private Charitable Contributions," Public Choice, 33 (1), 29-39.

Appel, Gil, Barak Libai, and Eitan Muller (2015), "How Free Digital Products Grow," MSI Reports, retrieved May 14, 2015, from: http://www.msi.org/reports/how-free-digitalproducts-grow/.

Askalidis, Georgios and Edward C. Malthouse (2016), "The Value of Online Customer Reviews," in Proceedings of the 10th ACM Conference on Recommender Systems, Boston, Massachusetts, USA: ACM, 155-58.

Aydinli, Aylin, Marco Bertini, and Anja Lambrecht (2014), "Price Promotion for Emotional Impact," Journal of Marketing, 78 (4), 80-96.

Batch, Bryan C., et al. (2014), "Weight Loss Intervention for Young Adults Using Mobile Technology: Design and Rationale of a Randomized Controlled Trial - Cell Phone Intervention for You (City)," Contemporary Clinical Trials, 37 (2), 333-41.

Bawa, Kapil and Robert Shoemaker (2004), "The Effects of Free Sample Promotions on Incremental Brand Sales," Marketing Science, 23 (3), 345-63.

Berger, Jonah (2014), "Word of Mouth and Interpersonal Communication: A Review and Directions for Future Research," Journal of Consumer Psychology, 24 (4), 586-607.

Berger, Jonah and Eric M. Schwartz (2011), "What Drives Immediate and Ongoing Word of Mouth?," Journal of Marketing Research, 48 (5), 869-80.

Biswas, Dipayan, Courtney Szocs, Roger Chacko, and Brian Wansink (2017), "Shining Light on Atmospherics: How Ambient Light Influences Food Choices," Journal of Marketing Research, 54 (1), 111-23.

Bryce, David J., Jeffrey H. Dyer, and Nile W. Hatch (2011), "Competing against Free," Harvard Business Review, 89 (6), 104-11.

Chandran, Sucharita and Vicki G. Morwitz (2006), "The Price of "Free"-Dom: Consumer Sensitivity to Promotions with Negative Contextual Influences," Journal of Consumer Research, 33 (3), 384-92.

Chen, Zoey (2017), "Social Acceptance and Word of Mouth: How the Motive to Belong Leads to Divergent WOM with Strangers and Friends, " Journal of Consumer Research, 44 (3), 613-632. 
Cheng, Hsing Kenneth and Yipeng Liu (2012), "Optimal Software Free Trial Strategy: The Impact of Network Externalities and Consumer Uncertainty," Information Systems Research, 23 (2), 488-504.

Chevalier, Judith A. and Dina Mayzlin (2006), "The Effect of Word of Mouth on Sales: Online Book Reviews," Journal of Marketing Research, 43 (3), 345-54.

Cialdini, Robert B., Joyce E. Vincent, Stephen K. Lewis, Jose Catalan, Diane Wheeler, and Betty Lee Darby (1975), "Reciprocal Concessions Procedure for Inducing Compliance: The Doorin-the-Face Technique," Journal of Personality and Social Psychology, 31 (2), 206-15.

Datta, Hannes, Bram Foubert, and Harald J. Van Heerde (2015), "The Challenge of Retaining Customers Acquired with Free Trials," Journal of Marketing Research, 52 (2), 217-34.

De Angelis, Matteo, Andrea Bonezzi, Alessandro Peluso, Derek Rucker, and Michele Costabile (2012), "On Braggarts and Gossips: A Self-Enhancement Account of Word-of-Mouth Generation and Transmission," Journal of Marketing Research, 49 (4), 551-563.

Dellarocas, Chrysanthos and Ritu Narayan (2006), "What Motivates Consumers to Review a Product Online? A Study of the Product-Specific Antecedents of Online Movie Reviews," paper presented at the Workshop on Information Systems and Economics (WISE), Evanston, IL.

Foubert, Bram and Els Gijsbrechts (2016), "Try It, You'll Like It-or Will You? The Perils of Early Free-Trial Promotions for High-Tech Service Adoption," Marketing Science, 35 (5), $810-26$.

Evans, David S. (2011), "The Antitrust Economics of Free," Competition Policy International, 7 (1), 71-89.

Gill, Manpreet, Shrihari Sridhar, and Rajdeep Grewal (2017), "Return on Engagement Initiatives: A Study of a Business-to-Business Mobile App," Journal of Marketing, 81 (4), 45-66.

Gouldner, Alvin W. (1960), "The Norm of Reciprocity: A Preliminary Statement," American Sociological Review, 25 (2), 161-78.

Hayes, Andrew F. (2013), Introduction to Mediation, Moderation, and Conditional Process Analysis, New York: Guilford Press.

He, Stephen X. and Samuel D. Bond (2015), "Why Is the Crowd Divided? Attribution for Dispersion in Online Word of Mouth," Journal of Consumer Research, 41 (6), 1509-27.

Hennig-Thurau, Thorsten, Kevin P. Gwinner, Gianfranco Walsh, and Dwayne D. Gremler (2004), "Electronic Word-of-Mouth Via Consumer-Opinion Platforms: What Motivates 
Consumers to Articulate Themselves on the Internet?," Journal of Interactive Marketing, 18 (1), 38-52.

Hoppner, Jessica J. and David A. Griffith (2011), "The Role of Reciprocity in Clarifying the Performance Payoff of Relational Behavior," Journal of Marketing Research, 48 (5), 92028.

Isen, Alice M., Thomas E. Shalker, Margaret Clark, and Lynn Karp (1978), "Affect, Accessibility of Material in Memory, and Behavior: A Cognitive Loop?," Journal of Personality and Social Psychology, 36 (1), 1-12.

Jones, Chuck (2013), "Apple's App Store About to Hit 1 Million Apps," Forbes, December 11.

Kronrod, Ann and Shai Danziger (2013), "“Wii Will Rock You!" the Use and Effect of Figurative Language in Consumer Reviews of Hedonic and Utilitarian Consumption," Journal of Consumer Research, 40 (4), 726-39.

Kumar, Vineet (2014), "Making "Freemium" Work: Many Start-Ups Fail to Recognize the Challenges of This Popular Business Model," Harvard Business Review, 92 (5), 27-29.

Lambrecht, Anja and Kanishka Misra (2017), "Fee or Free: When Should Firms Charge for Online Content?," Management Science, 63 (4), 1150-65.

Lee, Young-Jin, Kartik Hosanagar, and Yong Tan (2015), "Do I Follow My Friends or the Crowd? Information Cascades in Online Movie Ratings," Management Science, 61 (9), $2241-58$.

Moe, Wendy W. and David A. Schweidel (2012), "Online Product Opinions: Incidence, Evaluation, and Evolution," Marketing Science, 31 (3), 372-86.

Moore, Sarah G. (2015), "Attitude Predictability and Helpfulness in Online Reviews: The Role of Explained Actions and Reactions," Journal of Consumer Research, 42 (1), 30-44.

Newman, John M. (2015), "Antitrust in Zero-Price Markets: Foundations," University of Pennsylvania Law Review, 164 (1), 149-206.

Nicolau, Juan L (2012), "Battle Royal: Zero-Price Effect Vs Relative Vs Referent Thinking," Marketing Letters, 23 (3), 661-69.

Oh, Hyelim, Animesh Animesh, and Alain Pinsonneault (2016), "Free Versus for-a-Fee: The Impact of a Paywall on the Pattern and Effectiveness of Word-of-Mouth Via Social Media," MIS Quarterly, 40 (1), 31-A5.

Oppenheimer, Daniel M., Tom Meyvis, and Nicolas Davidenko (2009), "Instructional Manipulation Checks: Detecting Satisficing to Increase Statistical Power," Journal of Experimental Social Psychology, 45 (4), 867-72. 
Palmeira, Mauricio M. and Joydeep Srivastava (2013), "Free Offer $\neq$ Cheap Product: A Selective Accessibility Account on the Valuation of Free Offers," Journal of Consumer Research, 40 (4), 644-56.

Pauwels, Koen and Allen Weiss (2008), "Moving from Free to Fee: How Online Firms Market to Change Their Business Model Successfully," Journal of Marketing, 72 (3), 14-31.

Regan, Dennis T. (1971), "Effects of a Favor and Liking on Compliance," Journal of Experimental Social Psychology, 7 (6), 627-39.

Rick, Scott I., Cynthia E. Cryder, and George Loewenstein (2008), "Tightwads and Spendthrifts," Journal of Consumer Research, 34 (6), 767-82.

Schumann, Jan H., Florian von Wangenheim, and Nicole Groene (2014), "Targeted Online Advertising: Using Reciprocity Appeals to Increase Acceptance among Users of Free Web Services," Journal of Marketing, 78 (1), 59-75.

Shampanier, Kristina, Nina Mazar, and Dan Ariely (2007), "Zero as a Special Price: The True Value of Free Products," Marketing Science, 26 (6), 742-57.

Simonson, Itamar (1992), "The Influence of Anticipating Regret and Responsibility on Purchase Decisions," Journal of Consumer Research, 19 (1), 105-18.

Smith, Aaron and Monica Anderson (2016), "Online Shopping and E-Commerce," Pew Research Center.

Sun, Monic (2012), "How Does the Variance of Product Ratings Matter?" Management Science, 58 (4), 696-707.

Thomas, Manoj, Kalpesh Kaushik Desai, and Satheeshkumar Seenivasan (2011), "How Credit Card Payments Increase Unhealthy Food Purchases: Visceral Regulation of Vices," Journal of Consumer Research, 38 (1), 126-39

Weise, Elizabeth (2017), "Retailers Are Using Online Reviews from Other Sites to Fight Amazon," retrieved March 16, 2018, from: https://www.usatoday.com/story/tech/2017/12/12/930294001/.

White, Katherine, Lily Lin, Darren W. Dahl, and Robin J. B. Ritchie (2016), "When Do Consumers Avoid Imperfections? Superficial Packaging Damage as a Contamination Cue," Journal of Marketing Research, 53 (1), 110-23.

Wojnicki, Andrea C. and David Godes (2008), "Word-of-Mouth as Self-Enhancement," HBS Marketing Research Paper No. 06-01. 
Zhang, Yan and Nicholas Epley (2009), "Self-Centered Social Exchange: Differential Use of Costs Versus Benefits in Prosocial Reciprocity," Journal of Personality and Social Psychology, 97 (5), 796-810.

Zhang, Yinlong, Lawrence Feick, and Vikas Mittal (2014), "How Males and Females Differ in Their Likelihood of Transmitting Negative Word of Mouth," Journal of Consumer Research, 40 (6), 1097-108.

Zhu, Feng and Xiaoquan Zhang (2010), "Impact of Online Consumer Reviews on Sales: The Moderating Role of Product and Consumer Characteristics," Journal of Marketing, 74 (2), 133-48. 
Table 1

STUDY 4: SUMMARY STATISTICS

\begin{tabular}{|l|c|c|c|c|}
\hline & \multicolumn{2}{|c|}{ September 2014 } & \multicolumn{2}{c|}{ March 2015 } \\
\hline & Google Play & $\begin{array}{c}\text { Apple's App } \\
\text { Store }\end{array}$ & Google Play & $\begin{array}{c}\text { Apple's App } \\
\text { Store }\end{array}$ \\
\hline \multirow{2}{*}{ New Reviews } & $(1)$ & $(2)$ & $(3)$ & $(4)$ \\
\hline \multirow{2}{*}{ Free } & 863.404 & 202.325 & 753.743 & 132.452 \\
& $(6,587.073)$ & $(2,043.706)$ & $(4,351.575)$ & $(1,081.750)$ \\
\hline \multirow{2}{*}{ Prior Review Volume } & 0.679 & 0.635 & 0.684 & 0.641 \\
& $(0.467)$ & $(0.481)$ & $(0.465)$ & $(0.480)$ \\
\hline \multirow{2}{*}{ Prior Review Dispersion } & $8,915.005$ & $7,180.056$ & $14,638.600$ & $8,191.173$ \\
& $(42,197.590)$ & $(42,981.800)$ & $(81,428.460)$ & $(48,467.830)$ \\
\hline \multirow{2}{*}{ Prior Rating } & 1.300 & 1.254 & 1.329 & 1.283 \\
& $(0.426)$ & $(0.426)$ & $(0.388)$ & $(0.402)$ \\
\hline \multirow{2}{*}{ Overall Rank Top 500 } & 3.747 & 3.693 & 3.732 & 3.671 \\
& $(0.817)$ & $(0.919)$ & $(0.792)$ & $(0.905)$ \\
\hline \multirow{2}{*}{ Category Rank Top 500 } & 0.066 & 0.045 & 0.057 & 0.041 \\
& $(0.248)$ & $(0.207)$ & $(0.231)$ & $(0.198)$ \\
\hline Number of observations & 0.670 & 0.543 & 0.637 & 0.539 \\
& $(0.470)$ & $(0.498)$ & $(0.481)$ & $(0.499)$ \\
\hline
\end{tabular}


Table 2

STUDY 4: BASELINE RESULTS

\begin{tabular}{|c|c|c|c|c|}
\hline $\begin{array}{l}\text { Dependent variable: } \\
\Delta \Delta \log (\text { NewReviews })\end{array}$ & (1) & (2) & (3) & (4) \\
\hline$\Delta \Delta$ Free & $1.199 * * *$ & $1.229 * * *$ & $1.269 * * *$ & $1.294 * * *$ \\
\hline$\Delta \Delta \mathrm{LV}$ & $(0.176)$ & $\begin{array}{c}(0.170) \\
-0.094 \\
(0.061)\end{array}$ & $\begin{array}{c}(0.193) \\
-0.082 \\
(0.145)\end{array}$ & $\begin{array}{c}(0.189) \\
-0.087 \\
(0.144)\end{array}$ \\
\hline$\Delta \Delta \mathrm{HD}$ & & $\begin{array}{l}-0.069 \\
(0.047)\end{array}$ & $\begin{array}{l}-0.162 \\
(0.162)\end{array}$ & $\begin{array}{l}-0.209 \\
(0.163)\end{array}$ \\
\hline$\Delta \Delta$ Free* $\mathrm{LV}$ & & & $\begin{array}{l}-0.023 \\
(0.165)\end{array}$ & $\begin{array}{l}-0.012 \\
(0.164)\end{array}$ \\
\hline$\Delta \Delta$ Free*HD & & & $\begin{array}{c}0.062 \\
(0.175)\end{array}$ & $\begin{array}{c}0.113 \\
(0.176)\end{array}$ \\
\hline$\Delta \Delta \mathrm{LV} * \mathrm{HD}$ & & & $\begin{array}{c}0.340^{* *} \\
(0.168)\end{array}$ & $\begin{array}{c}0.382 * * \\
(0.170)\end{array}$ \\
\hline$\Delta \Delta$ Free $^{*} \mathrm{LV} * \mathrm{HD}$ & & & $\begin{array}{c}-0.403 * * \\
(0.187)\end{array}$ & $\begin{array}{c}-0.447 * * \\
(0.188)\end{array}$ \\
\hline$\Delta \Delta$ Rating & & $\begin{array}{l}-0.006 \\
(0.065)\end{array}$ & & $\begin{array}{l}-0.001 \\
(0.065)\end{array}$ \\
\hline$\Delta \Delta$ OverallTop500 & & $\begin{array}{c}0.371 * * * \\
(0.078)\end{array}$ & & $\begin{array}{c}0.377 * * * \\
(0.078)\end{array}$ \\
\hline$\Delta \Delta$ CategoryTop 500 & & $\begin{array}{c}0.140 * * * \\
(0.026)\end{array}$ & & $\begin{array}{c}0.139 * * * \\
(0.026)\end{array}$ \\
\hline Observations & 5,665 & 5,665 & 5,665 & 5,665 \\
\hline R-square & 0.016 & 0.023 & 0.020 & 0.032 \\
\hline
\end{tabular}

Notes: Robust standard errors in parentheses; ${ }^{* * *} p<0.01,{ }^{* *} p<0.05, * p<0.1 ; \Delta \Delta$ indicates differences between the two platforms and between the two points in time. 
Table 3

STUDY 4: MARGINAL EFFECTS

\begin{tabular}{|c|c|c|c|}
\hline \multicolumn{2}{|c|}{ Effects of changing } & from paid to free on new posts \\
\hline Low Volume + & Low Volume + & High Volume + & High Volume + \\
Low Dispersion & High Dispersion & Low Dispersion & High Dispersion \\
\hline $1.282^{* * *}$ & $0.948^{* * *}$ & $1.294 * * *$ & $1.407 * * *$ \\
$(0.187)$ & $(0.199)$ & $(0.189)$ & $(0.213)$ \\
\hline
\end{tabular}

Notes: Marginal effects are calculated based on estimates in column (4) of Table 2; robust standard errors in parentheses; the difference between low-volume-high-dispersion and the other three conditions is statistically significant $(\mathrm{p}=0.001,0.045,0.005) ; * * * p<0.01, * * p<0.05, *$ $p<0.1$. 
Figure 1

\section{MECHANISMS THAT DRIVE SHARING}

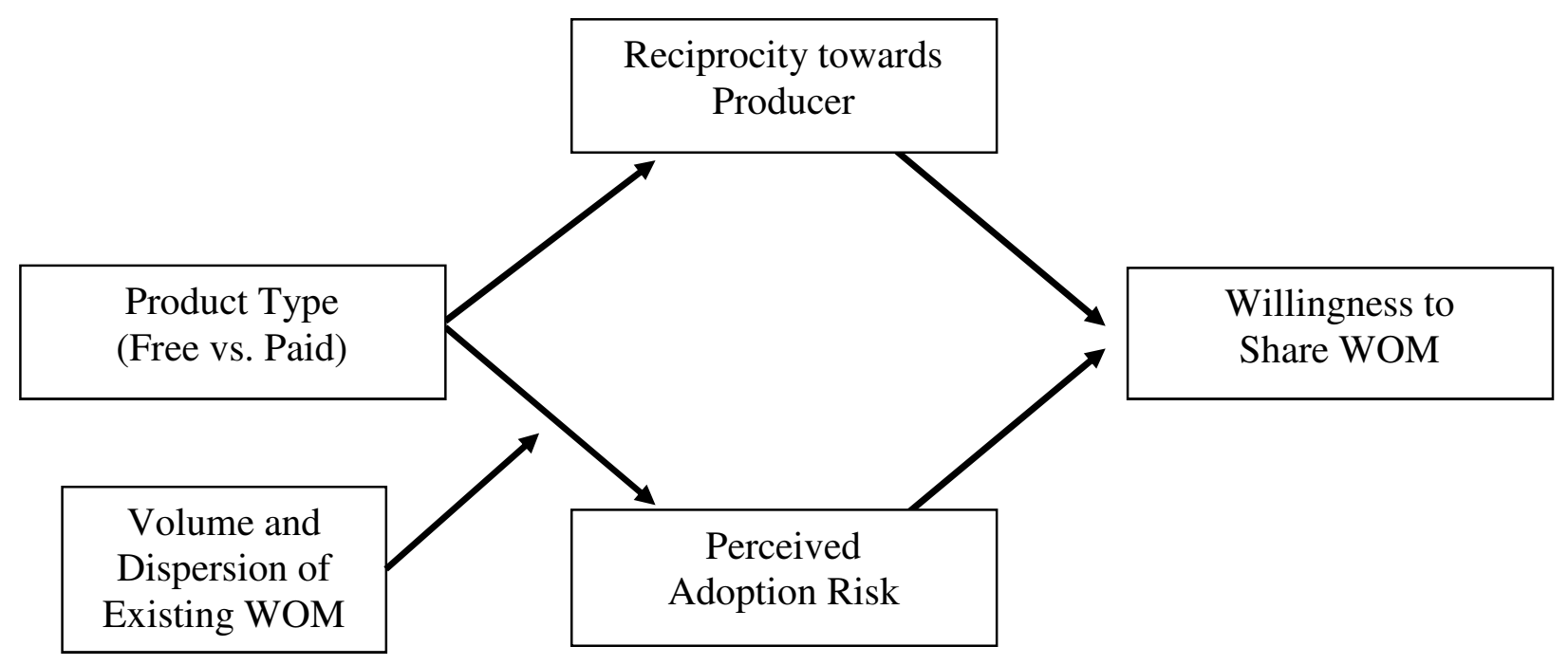


Figure 2

WOM DISTRIBUTIONS FOR STUDY 2

\begin{tabular}{|c|c|}
\hline Low-volume-low-dispersion & Low-volume-high-dispersion \\
\hline 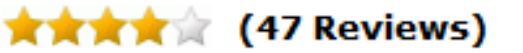 & 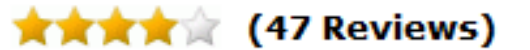 \\
\hline 4.0 out of 5 stars & 4.0 out of 5 stars \\
\hline 5 star & 5 star \\
\hline 4 star & 4 star \\
\hline 3 star & 3 star \\
\hline 2 star & 2 star \\
\hline 1 star & 1 star \\
\hline High-volume-low-dispersion & High-volume-high-dispersion \\
\hline (987 Reviews) & (987 Reviews) \\
\hline 4.0 out of 5 stars & 4.0 out of 5 stars \\
\hline 5 star & 5 star \\
\hline 4 star & 4 star \\
\hline 3 star & 3 star \\
\hline 2 star & 2 star \\
\hline 1 star & 1 star \\
\hline
\end{tabular}


Figure 3

STUDY 2: EFFECTS OF WOM VOLUME, WOM DISPERSION, AND PRODUCT TYPE ON CHOOSING WHETHER TO POST A REVIEW

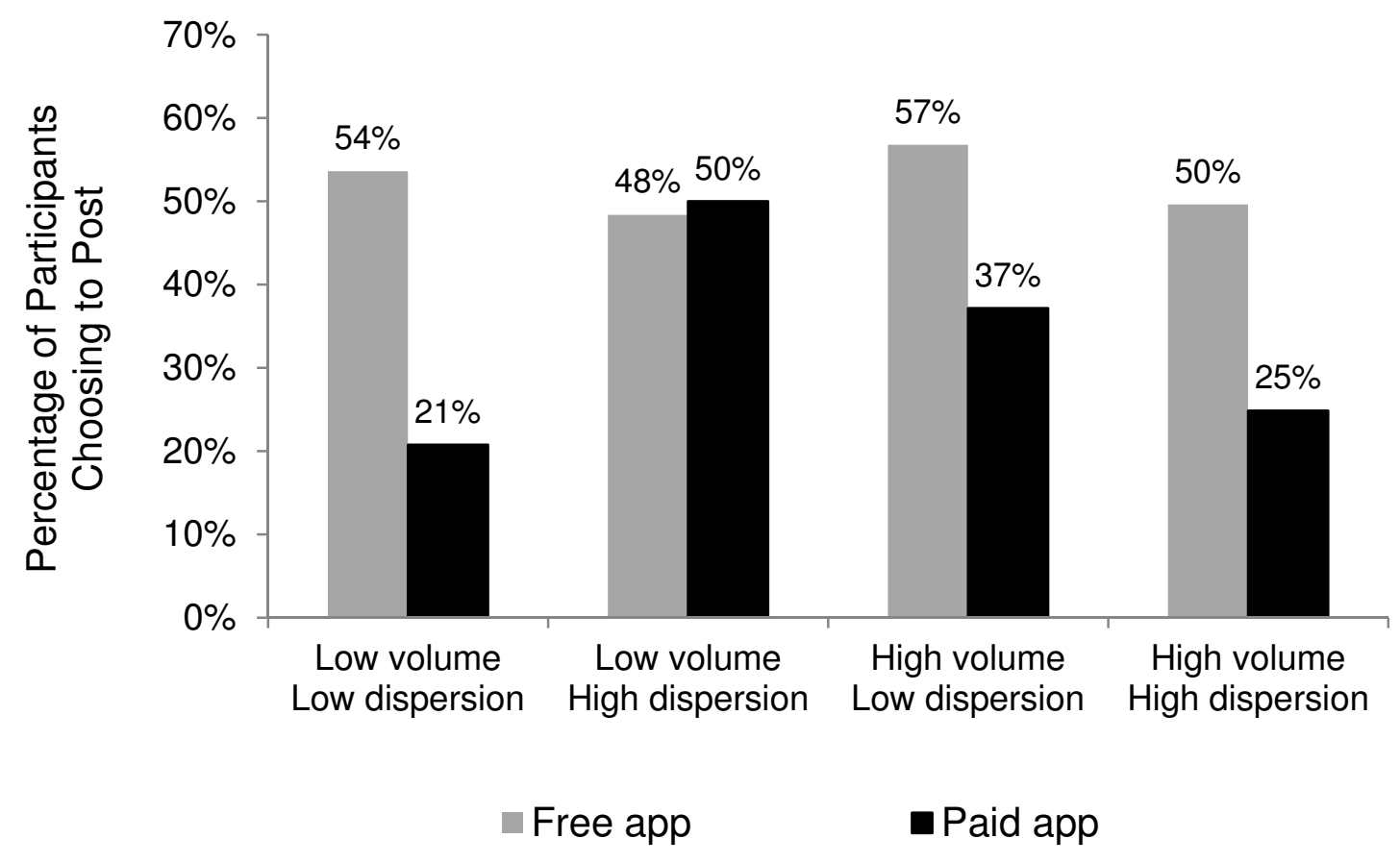


Figure 4

STUDY 3: EFFECTS OF WOM VOLUME, WOM DISPERSION, AND PRODUCT TYPE ON INTENTION TO POST A REVIEW

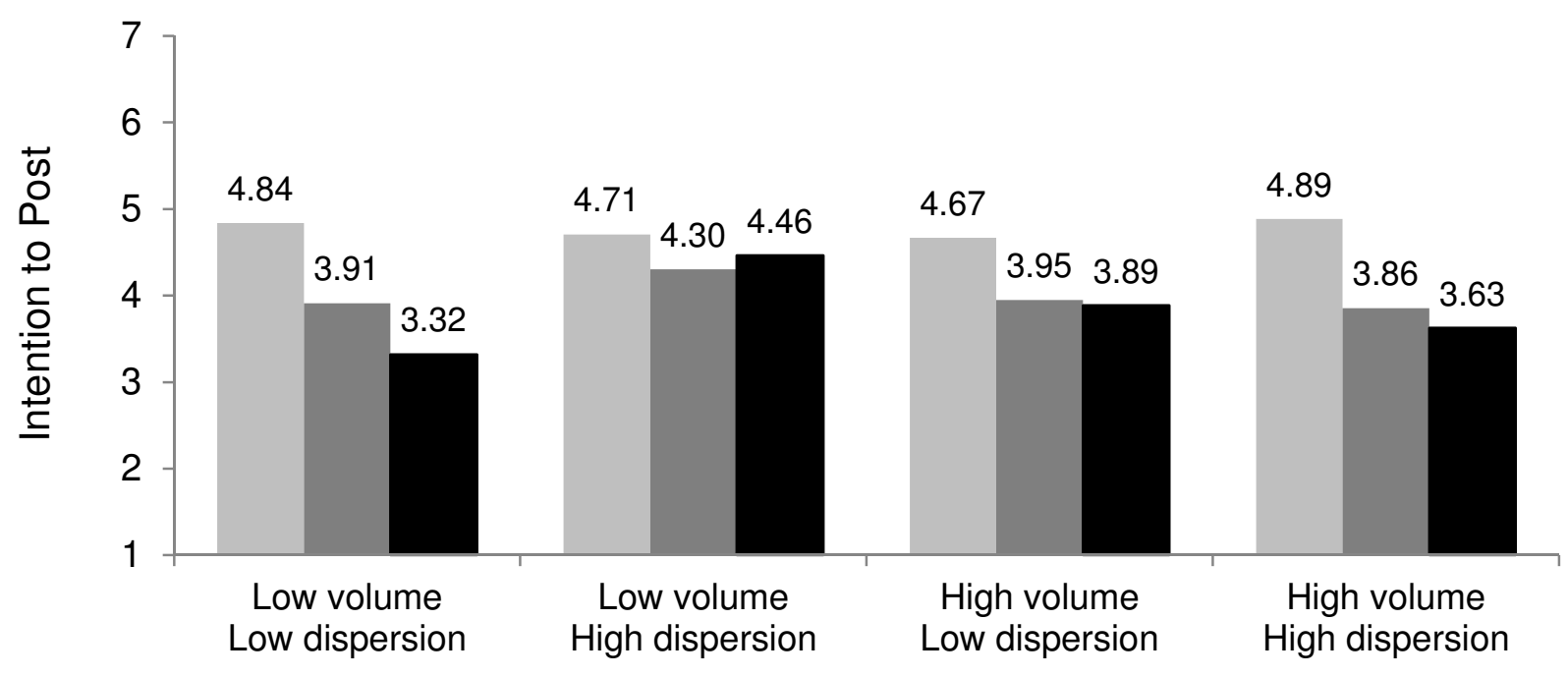

Free app $\quad$ Free+ads app $\quad$ Paid app 
Figure 5

\section{STUDY 4: DESCRIPTIVE EVIDENCE}

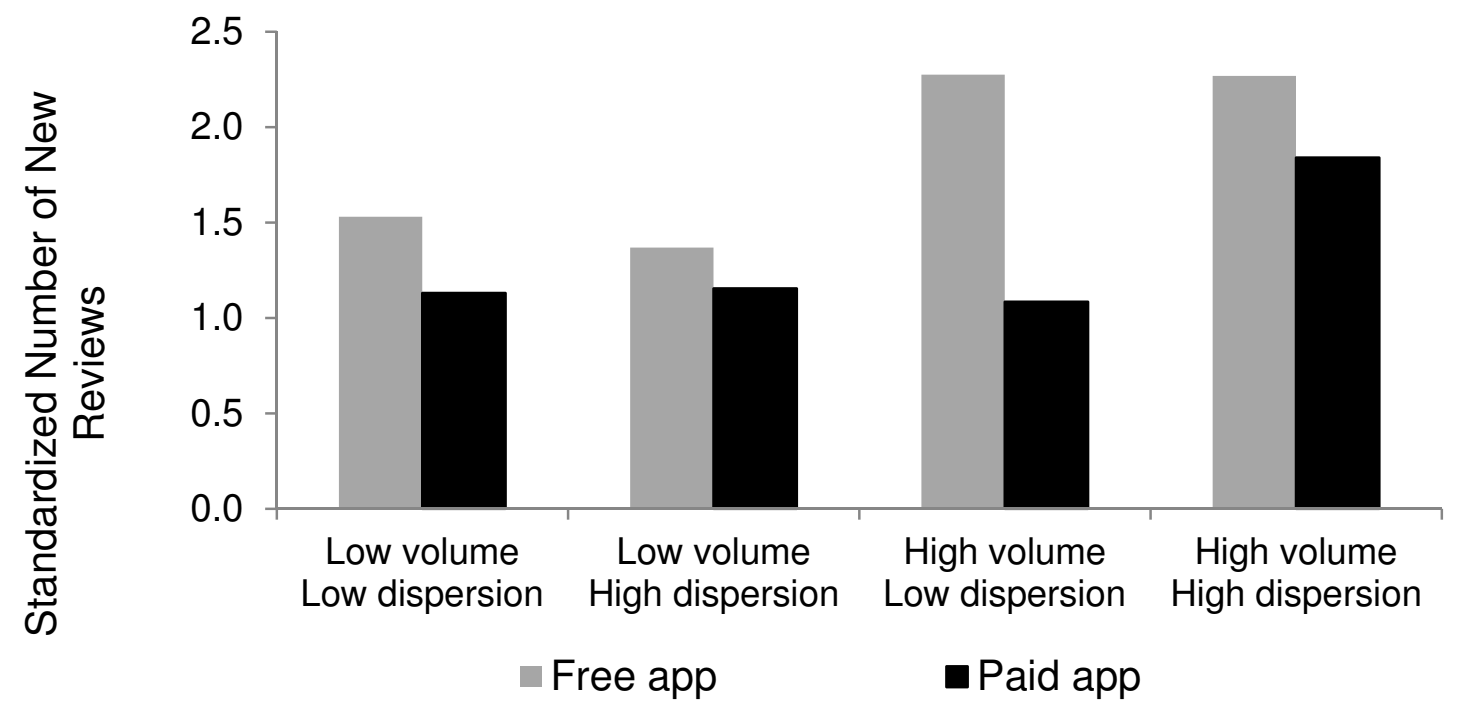

Notes: The chart is based on the September 2014 sample; a standardized measure is used to account for heterogeneity across the two platforms; "high and "low" levels are defined by a median split; the difference between free and paid apps is significant for the "low volume and low dispersion", "high volume and low dispersion", and "high volume and high dispersion" groups (all $p s<.06$ ), but not for the "low volume and high dispersion" group. 


\section{Web Appendixes}


Web Appendix A

WEB APP FOR STUDY 2
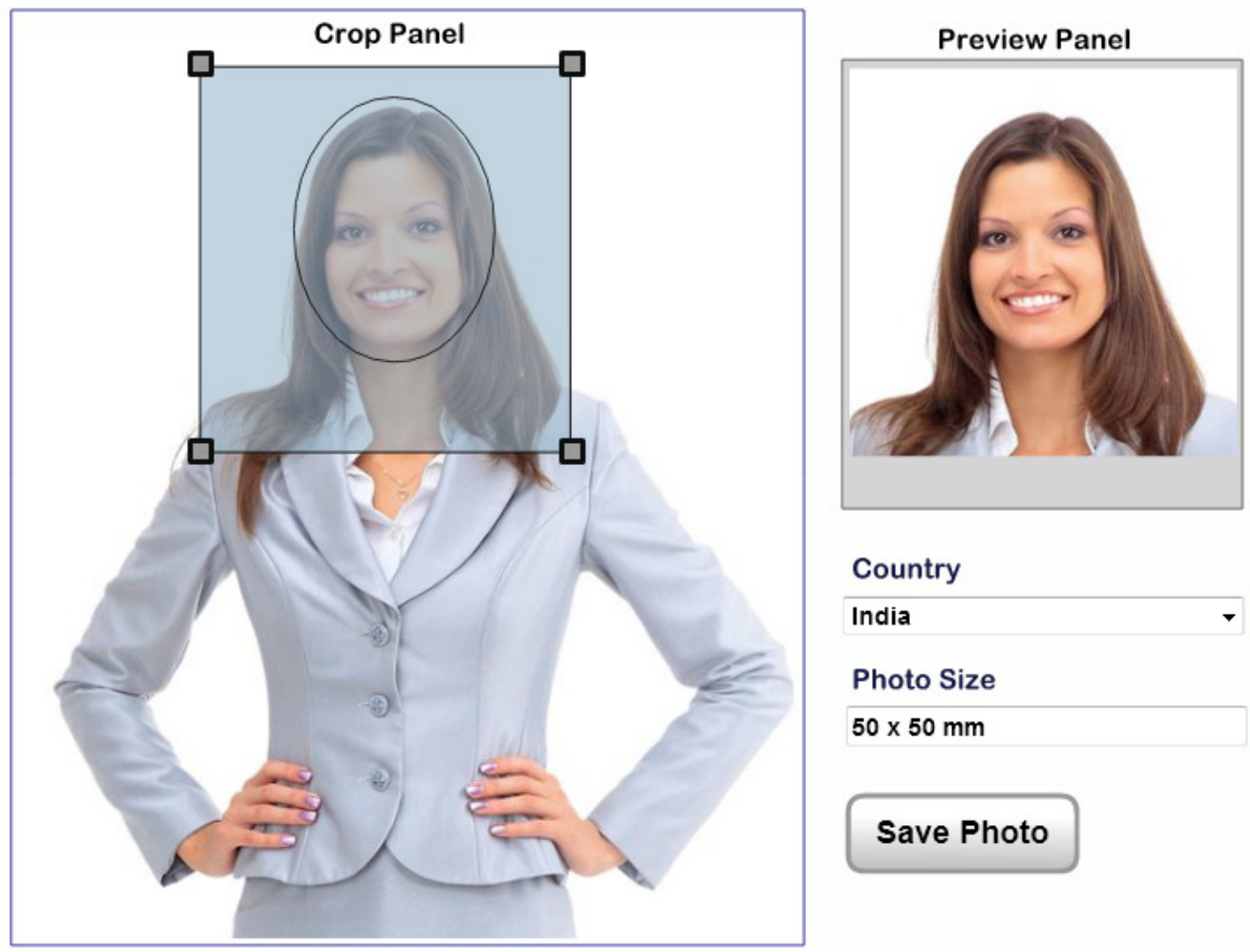

Country

India

Photo Size

$50 \times 50 \mathrm{~mm}$

Save Photo 


\section{Web Appendix B}

\section{STUDY 2: PRETEST FOR PRODUCT TYPE, VOLUME AND DISPERSION MANIPULATOINS}

We conducted a separate pretest to ensure that the product type, volume, and dispersion manipulations were perceived as intended. The pretest included scales adapted from Rick, Cryder, and Loewenstein (2008), Thomas, Desai, and Seenivasan (2011), and He and Bond (2015). Eighty-one participants from Mechanical Turk were randomly assigned to the same eight conditions as the main study, underwent the same initial procedure, and then answered questions regarding all three manipulations. Compared to participants in the paid conditions, those in the free conditions reported less pain of paying $(1$ - not painful at all / $\odot, 7$ - extremely painful / $:$; $M=1.21$ vs. $3.55 ; F(1,73)=65.78, p<.001)$, and also perceived more value $(1-$ very poor value, 7 - very good value; $M=6.59$ vs. $5.58 ; F(1,73)=14.80, p<.001)$. Compared to participants in the low-volume conditions, those in the high-volume conditions perceived that the app had received more prior reviews $(1-$ very few, 7 - a lot; $M=5.78$ vs. $4.07 ; F(1,73)=28.59$, $p<.001)$. Compared to participants in the low-dispersion conditions, those in the high-dispersion conditions perceived that user ratings were more spread out (1 - very close together, 7 - very spread out; $M=3.88$ vs. $2.64 ; F(1,73)=14.39, p<.001)$. 


\section{Web Appendix C \\ CONTROLLED EXPERIMENT - CHOICE BETWEEN APPS}

The design of this experiment was similar to that in Study 2, with two main exceptions. First, participants were given the opportunity to choose between alternative apps before experiencing their choice and deciding whether to post a review. The additional task was likely to generate noise and reduced the impact of the manipulations, making this a conservative design. Moreover, we expected that the addition of a choice would increase the likelihood of sharing in general, due to increased involvement and investment in the decision, as well as the possibility of using the review to reduce post-choice dissonance (Brehm 1956). However, we predicted that both the "reciprocity" and "risk" pathways in our model to remain active, in which case the pattern of sharing across conditions would be consistent with those in Study 2.

The second change was the addition of a new, "discounted" price condition. Given the wideranging effects of price promotion on consumer inferences and response (Gupta and Cooper 1992; Raghubir, Inman, and Grande 2004), the discounted condition was largely exploratory. To the extent that "free" is perceived as a category rather than a continuum, however, even a substantial discount would be unlikely to generate substantial reciprocity or inferences of risk reduction; if so, then our theorizing predicts a pattern of results that is similar in shape to that of the paid conditions.

\section{Method}

Experimental Procedure. Seven-hundred-and-nine U.S. residents were recruited from Mechanical Turk and compensated for their participation. Sample size considerations were based 
on effect sizes observed in Study 2. Participants were randomly assigned to one of twelve conditions in a 3 (product type: free vs. discounted vs. paid $) \times 2$ (WOM volume: low vs. high $) \times$ 2 (WOM dispersion: low vs. high) between-subjects design.

The setup and procedure of the study was identical to that of Study 2, with two important modifications. First, the scenario asked participants to "choose" between two alternative photo apps, based on the prior distribution of consumer reviews. One of the two alternatives was the target app (GlobalVisaPhoto), and the other alternative was a decoy (Visafoto). To ensure that the decoy alternative would be unattractive, its distribution presented a low average rating (two out of five stars), along with moderate volume (217 reviews) and moderate dispersion (SD = 1.00). The review distributions for the target app (GlobalVisaPhoto) varied by condition and were identical to those in Study 2. Only thirteen participants chose the decoy, and their data were discarded prior to analysis.

As in Study 2, participants in the free condition were told that the photo app was free of charge, and participants in the paid condition were told that each photo cost 50 cents. In the new, "discounted" condition, participants were told that although the "normal price" was 50 cents per photo, that they had received a first-time user discount and would only pay 25 cents per photo. As before, participants in the paid conditions went through the process of "paying" for their selected app out of their study compensation.

After experiencing the app, participants completed evaluation, review, and process measures similar to those in Study 2. As before, willingness to post a review was measured with a binary (yes/no) decision. In addition, participants completed a more sensitive dependent measure asking how motivated they would be to post a star rating and a text review (1 - not very motivated, 7 very motivated). Participants who answered "yes" to the binary question were asked to write a 
text review of the app and also to answer an open-ended question: "What is your opinion about the developers of GlobalVisaPhoto? What are your feelings towards them?"

\section{Results}

Descriptive Statistics. Based on the same filtering criteria used in Study 2, data from 97 participants were removed, leaving a sample of $612(52 \%$ female, mean age $=37)$. As expected, participants were generally satisfied with the app $(M=6.13, S D=1.05)$. Satisfaction was directionally higher than that observed in Study $2(M=5.65)$, suggesting that the addition of the choice task may have evoked post-choice dissonance reduction.

Posting Choice and Motivation. Table C-1 depicts the proportion of participants in each condition who agreed to post a review. Examination of the figure reveals a pattern consistent with that obtained in Study 2: in particular, participants were generally more willing to post a review for a free than a paid app, but this difference nearly disappeared when prior reviews for the app were low in volume and highly disperse. However, the thee way product type $\times$ volume $\times$ dispersion interaction effect was not significant $\left(\chi^{2}(1)=.49, p=.48\right)$.

\section{[Insert Table C-1 about here]}

Motivation to post is depicted in Table C-2 and was examined via an ANOVA including product type, review volume, and review dispersion as fixed explanatory factors. Results revealed a significant main effect of product type $(F(2,600)=9.53, p<.001)$ consistent with the Study 2: participants expressed greater willingness to post a review when the app was free than paid $(M=4.37$ vs. $3.24 ; F(1,600)=14.37, p<.001)$. Motivation to post in the new, discounted condition $(M=3.65)$ was significantly lower than that in the free condition $(F(1,600)=14.07, p$ $<.001)$ but was not reliably different from that in the paid condition $(F(1,600)<1)$. 
[Insert Table C-2 about here]

Most important, analyses also revealed a significant product type $\times$ volume $\times$ dispersion interaction effect $(F(2,600)=3.23, p<.05)$. To decompose the interaction, we tested three partial interaction contrasts that each included two levels of product type. Results were significant for the test comparing free and paid $(F(1,600)=4.23, p<.05)$ and for the test comparing discounted and paid, $(F(1,600)=5.54, p<.05)$, but were not significant for the test comparing free and discounted $(F(1,600)<1)$. Therefore, our follow-up analysis focused on the free and paid conditions.

To explore the three-way interaction, we conducted separate follow-up contrasts at each level of existing volume. The pattern of results was consistent with hypotheses and the findings of Study 2. When existing WOM volume was high, results revealed only a main effect of product type $(F(1,600)=11.29, p<.01):$ participants were more motivated to post a review when the app was free than when it was paid, whether the dispersion was low ( $M=4.21$ vs. $3.56 ; F(1$, $600)=2.39, p=.12)$ or high $(M=4.45$ vs. $3.10 ; F(1,600)=10.23, p<.001)$. When existing volume was low, however, results revealed a marginal product type $\times$ dispersion interaction $(F(1$, $600)=2.97, p<.10)$. Follow-up comparisons revealed that when dispersion was also low, motivation to post was greater when the app was free than paid $(M=4.37$ vs. $3.26 ; F(1,600)=$ $6.76, p=.01)$. When dispersion was high, however, the difference between free and paid conditions was negligible $(M=4.13$ vs. $4.04 ; F(1,600)<1, p>.30)$.

Intention to Reciprocate. Analysis of the intention to reciprocate measure via ANOVA revealed a significant main effect of product type $(F(1,600)=17.50, p<.001)$. On average, participants were more willing to reciprocate when the app was free $(M=5.47)$ than when it was discounted $(M=4.67 ; F(1,600)=26.98, p<.001)$ or paid $(M=4.67 ; F(1,600)=25.20, p$ 
$<.001)$. The difference between discounted and paid conditions was not significant $(F(1,600)$ $<1, p>.30)$.

To formally explore the proposed reciprocity pathway in the free and paid conditions, we conducted a mediation analysis using the same process described in Study 2. Results revealed a marginal indirect effect of product type on motivation to post through intention to reciprocate (B $=-.42, \mathrm{SE}=.26,90 \% \mathrm{CI}=[-.85,-.01])$. However, results did not support a mediating role for attitude towards the app $(\mathrm{B}=.01, \mathrm{SE}=.04,90 \% \mathrm{CI}=[-.05, .10])$.

Text Analysis of Reciprocity. As an additional, exploratory investigation of reciprocity, we examined responses to the open-ended question (written by the subsample of participants who chose to post a review). Using a thesaurus, we identified reciprocity-related keywords (including "appreciate," "grateful," "thank," "indebted," and variations of these words). Two independent coders, blind to the hypotheses, then coded for the presence of these words in each response. Intercoder reliability was high $(\mathrm{r}=98 \%)$, and disagreement was resolved by discussion.

Analysis revealed that reciprocity-related words were used by $71 \%$ of review writers in the free condition, compared to $58 \%$ in the paid condition $\left(\chi^{2}(1)=3.21, p=.07\right)$. For the most frequently mentioned word ("grateful"), the difference was $53 \%$ vs. $30 \%\left(\chi^{2}(1)=9.77, p<.01\right)$. These differences suggest that among participants who chose to write a review, those who had paid nothing for the app felt more indebted to the developer than those who had paid for it. Given the limitations of this analysis (and especially the use of a selective sample), however, the evidence should be considered preliminary.

Perceived Adoption Risk. Analysis of the adoption risk measure via ANOVA revealed a significant main effect of product type $(F(2,600)=4.70, p<.01)$, such that participants perceived the free app $(M=2.07)$ to carry less adoption risk than either the discounted app ( $M=$ 
$2.26 ; F(1,600)=4.49, p<.01)$ or the paid app $(M=2.34 ; F(1,600)=8.82, p<.001)$. The difference between discounted and paid conditions was not significant $(F(1,600)<1, p>.30)$. Most important, analysis revealed a marginal product type $\times$ volume $\times$ dispersion interaction effect $(F(2,600)=2.39, p<.10)$, and planned contrasts revealed a pattern consistent with predictions. When volume was low and dispersion was high, participants perceived lower risk when the app was free $(M=2.05)$ than when it was discounted $(M=2.14 ; F(1,600)<1, p>.30)$ or paid $(M=2.67 ; F(1,600)=12.01, p<.001)$; the main effect of product type was not significant for any other combination of volume and dispersion. However, mediation analyses of the risk pathway was inconclusive $(\mathrm{B}=.01, \mathrm{SE}=.08,95 \% \mathrm{CI}=[-.10, .16])$.

\section{Discussion}

By requiring participants to actually "choose" the app that they would be experiencing, this experiment added an additional layer of realism to the design introduced in Study 2. The primary findings were consistent with our hypotheses and findings of Studies 2-3, suggesting that the effects of product type proposed in our framework are observable in actual consumer experience.

Findings for the new, discounted condition were exploratory but suggestive: overall, results for the discounted condition closely resembled those for the paid condition, and were distinct from those for the free condition. In particular, participants were less likely to share WOM for the app when it was discounted than when it was free, and the discount was largely ineffective at evoking reciprocity.

\section{REFERENCES}


Brehm, Jack W. (1956). "Postdecision Changes in the Desirability of Alternatives," The Journal of Abnormal and Social Psychology, 52(3), 384.

Gupta, Sunil and Lee G. Cooper (1992), "The Discounting of Discounts and Promotion Thresholds," Journal of Consumer Research, 19 (3), 401-11.

Raghubir, Priya, J. Jeffrey Inman, and Hans Grande (2004), "The Three Faces of Consumer Promotions," California Management Review, 46 (4), 23-42. 
Table C-1

\section{EFFECTS OF WOM VOLUME, WOM DISPERSION, AND PRODUCT TYPE ON} CHOOSING WHETHER TO POST A REVIEW

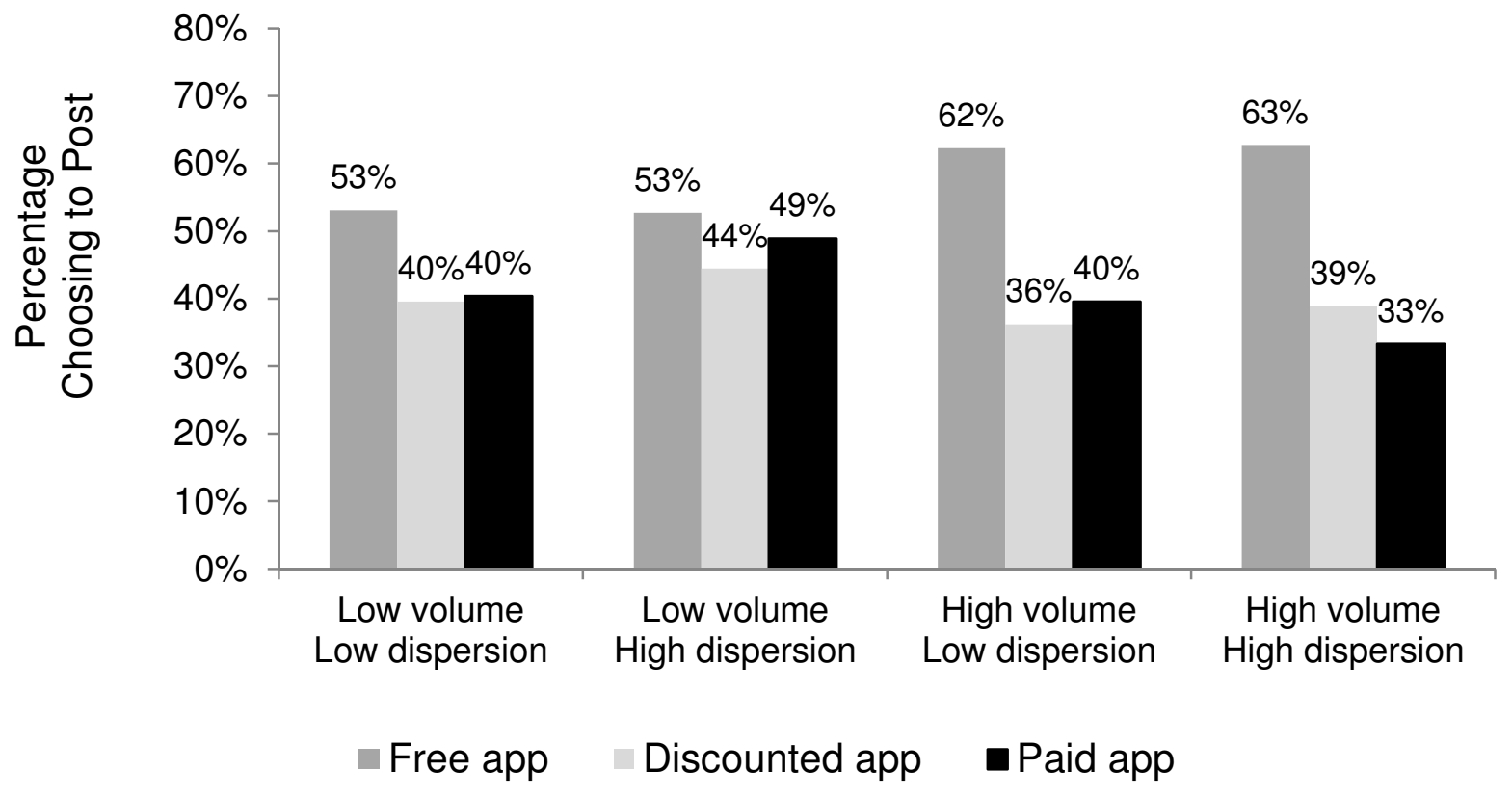


Table C-2

\section{EFFECTS OF WOM VOLUME, WOM DISPERSION, AND PRODUCT TYPE ON MOTIVATION TO POST A REVIEW}

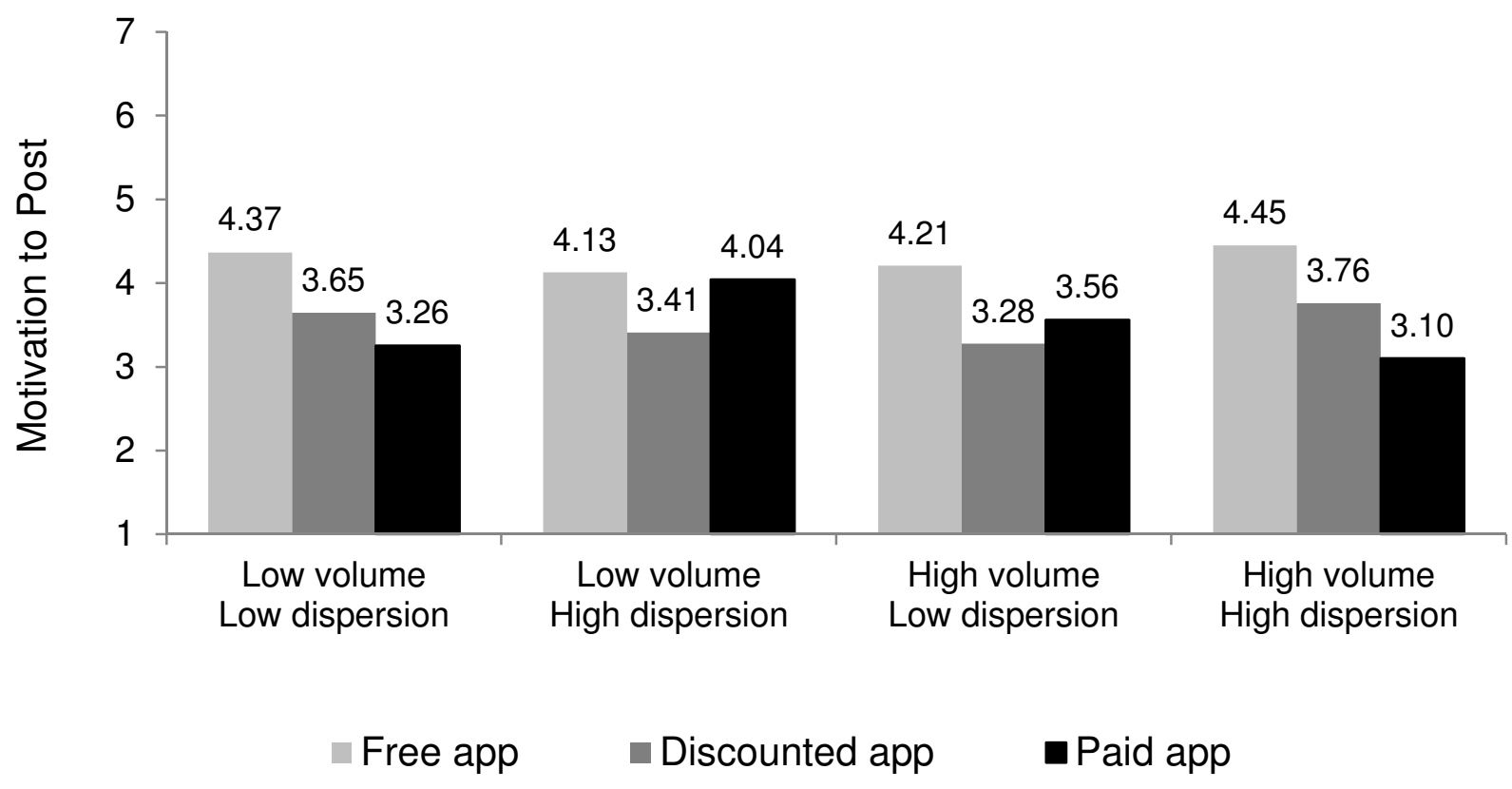




\section{Web Appendix D}

\section{STIMULI FOR STUDY 3}

[Bold, normal, and italicized terms in brackets were presented to participants in the free/ad-free condition, free/ads condition, and paid condition, respectively.]

\section{Mobile App Scenario}

Please imagine the following:

You have heard a lot about different smartphone apps related to nutrition and health, and you are interested in finding one of these apps to try for yourself. Therefore, you spend some time reading about different apps in this category.

One of the apps you find is the following:

HealthyU

(available for iPhone, Android, and Windows Phone)

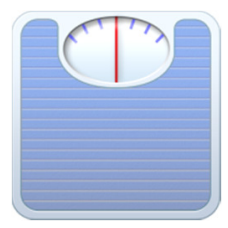

\section{Description:}

The purpose of HealthyU is to provide a simple and effective means for people to control their weight and maintain a healthy lifestyle. This smartphone app is developed by a software start-up company based in Palo Alto, California. In addition to HealthyU, the develop team has created a variety of other consumer health related apps.

The App offers a variety of important features to support healthy behavior, such as the following:

- $\quad$ Food tracking. You can track everything you eat (meats, fruits, vegetables, beverages, etc.) throughout a day, along with its nutritional content.

- Physical activity tracking. Based on the type and duration of your activities throughout the day, the app provides information about activity level, calories burned, etc.

- $\quad$ Buddy system. (Optional) If you want, the app can pair you randomly and anonymously each month with a "buddy" who is also using the app. Buddies can send each other messages, encouragement, advice, or tips for meeting lifestyle challenges.

- Goal setting. You can set your own goal, or select from a list of pre-determined goals. The app provides periodic feedback on your progress toward that goal.

- Weight tracking. As new measurements are entered, a historical weight graph is updated.

Cost: 
The basic version of HealthyU [is free of charge and does not show any advertising / is free of charge but shows sponsored ads every time that the app is activated / costs $\$ 2.99$ and does not show any advertising]. The basic version is fully functional, and can be upgraded to an advanced version for a fee.

Many similar health and nutrition apps [charge a fee for their basic versions, sometimes \$2.99 or more / are free to use, and they do not show sponsored ads / charge nothing for their basic versions and are free to use].

[next screen]

Next, please imagine the following:

After reading about HealthyU, you decided to download the basic version of the app and install it on your phone.

\section{Over the next few weeks}

You begin to familiarize yourself with HealthyU. The app takes some time to get used to, but eventually you grow more comfortable with the functions and find them to be useful. You appreciate some of the unique HealthyU features not found in other popular health apps - for example, its 'DASH' eating plan ("Dietary Approaches to Stop Hypertension").

\section{Two months later}

You have used HealthyU regularly. With the help of the app, you have been able to maintain a number of healthy behaviors, such as: recording what you eat (3-4 days per week), keeping calories in moderation by following the eating plan, tracking your daily activity levels, getting at least $180 \mathrm{~min}$ of exercise per week, limiting stress, etc.

For the most part, you feel that you have been keeping your diet in check while enjoying a healthier, more energetic lifestyle. Therefore, you are satisfied overall with your experience with HealthyU.

[next screen]

As you are opening the HealthyU app one day, you receive the following popup message:

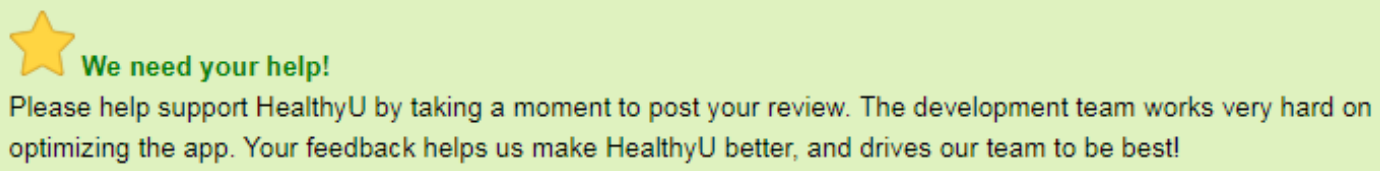

If you agree, your review will be posted at the app store.

Before you decide whether to post a review for HealthyU, please click "Next" to see a summary of its existing reviews at the app store. 


\section{Web Appendix E}

\section{STUDY 3 RESULTS WITH FAMILIARITY CONTROL}

Intention to Post. To investigate our hypotheses, we conducted an ANOVA on intention to

post as a function of product type, WOM volume, WOM dispersion, their interactions, and familiarity as a control variable. Results revealed a significant main effect of product type $(F(2$, $670)=16.55, p<.001)$. As predicted, participants expressed greater willingness to post a review when the app was free than paid $(M=4.75$ vs. $3.81 ; F(1,670)=28.56, p<.001)$. Intention to post in the new, free+ads condition $(M=3.98)$ was significantly lower than that in the free condition $(F(1,670)=20.04, p<.001)$, but only directionally higher than that in the paid condition $(F(1,670)=.90, p=.34)$. Most important, analyses revealed a significant product type $\times$ volume $\times$ dispersion interaction $(F(2,670)=2.99, p=.05)$. When existing WOM volume was high, results revealed only a main effect of product type $(F(2,670)=9.74, p<.001)$, such that participants were more likely to post a review when the app was free than when it was free with ads or paid, regardless of dispersion. When existing volume was low, however, results revealed a significant product type $\times$ dispersion interaction $(F(2,670)=3.13, p<.05)$, showing product type difference only when dispersion was also low.

Intention to Reciprocate. ANOVA revealed a main effect of product type $(F(2,670)=$ 17.77, $p<.001)$, such that intention to reciprocate was higher in the free condition than the free+ads condition $(M=5.50$ vs. $4.96 ; F(1,670)=16.91, p<.001)$ or the paid condition $(M=$ $4.72 ; F(1,670)=33.38, p<.001)$; the difference between the free+ads and paid conditions was marginally significant $F(1,670)=3.03, p=.08)$. As a formal test of the pathway, we conducted a mediation analysis similar to that in Study 2. Consistent with predictions, results revealed an 
indirect, negative effect of product type on intention to post a review through intention to reciprocate $(\mathrm{B}=-.86, \mathrm{SE}=.21,95 \% \mathrm{CI}=[-1.27,-.46])$.

We next examined the potential roles of attitude towards the app, self-serving motivation, and chance of survival, by including these variables in the mediation model simultaneously with intention to reciprocate. Results did not reveal a significant mediating role for attitude towards the app or self-serving motivation ( $95 \%$ CIs included zero). Results did reveal a mediating role for chance of survival $(\mathrm{B}=-.17, \mathrm{SE}=.09,95 \% \mathrm{CI}=[-.37,-.03])$, suggesting that participants more willing to post reviews for free apps due to the perception that they were more likely to survive. However, results continued to reveal a mediating role for intention to reciprocate $(\mathrm{B}=$ $-.68, \mathrm{SE}=.18,95 \% \mathrm{CI}=[-1.06,-.33])$.

Perceived Adoption Risk. ANOVA revealed significant main effects of product type $(F(2$, $670)=4.14, p<.05)$, volume $(F(1,670)=16.56, p<.001)$, and dispersion $(F(1,670)=19.11, p$ $<.001)$. Most important, results also revealed a marginal product type $\times$ volume $\times$ dispersion interaction effect $(F(2,670)=2.50, p=.08)$, whose pattern was consistent with predictions. Planned contrasts revealed that when volume was low and dispersion was high, participants perceived lower risk when the app was free than when it had ads or was paid $(M=2.83$ vs. 3.37 ; $F(1,670)=10.90, p<.001 ;$ vs. $3.44 ; F(1,670)=14.25, p<.001)$; the difference between the free+ads and paid conditions was not significant $(p>.30)$. For all other combinations of volume and dispersion, the effect of product type was not significant $(p>.30)$.

Consistent with predictions, mediation analysis revealed an indirect, positive effect of product type on intention to post through perceived adoption risk, moderated by the volume $\times$ dispersion interaction $(\mathrm{B}=-.15, \mathrm{SE}=.11,95 \% \mathrm{CI}=[-.42, .00])$. Follow-up analyses revealed evidence for the indirect effect when volume was low and dispersion was high $(\mathrm{B}=.13, \mathrm{SE}$ 
$=.08,95 \% \mathrm{CI}=[.01, .30])$, but not for any of the other volume $\times$ dispersion conditions (all CIs included zero). 


\section{Web Appendix F}

\section{ROBUSTNESS CHECKS FOR STUDY 4}

First, we employed a continuous measure for existing review volume and review dispersion. Because prior review volume is highly skewed, we used the log transformation (denoted as $\log ($ Volume $)$ ). Regression results and estimated marginal effects are shown in Table

F-1 and F-2. Caution should be taken interpreting these results, due to high intercorrelations: the correlation between $\Delta \Delta$ Free and $\Delta \Delta$ Free* $\log ($ Volume $)$ was 0.8 , and the correlation between $\Delta \Delta$ Free and $\Delta \Delta$ Free* $\log ($ Volume $) *$ Dispersion was 0.7 . Results revealed a significant positive coefficient for $\Delta \Delta$ Free and $\Delta \Delta$ Free* $\log (\text { Volume })^{*}$ Dispersion. The marginal effect of changing from paid to free was again smallest in the low-volume, high-dispersion condition, although the marginal effect in this condition was not significantly different from that in the high-volume, high-dispersion condition (Table F-2).

Second, our model assumes that the consumers are at least moderately satisfied with their product experience. Therefore, we restricted the analysis to the subsample of apps with average ratings of at least four (out of five) at both platforms. Results are reported in Tables F-3 and F-4, and are qualitatively similar to the baseline results.

Third, we implementing a cross-sectional analysis following the approach of Chevalier and Mayzlin (2006). The analysis utilized only the September 2014 sample and was based on model specification (2). Regression results are reported in Tables F-5 and F-6, and are qualitatively similar with the baseline results. 
Table F-1: Continuous Measure of Prior Review Volume and Dispersion

\begin{tabular}{|c|c|c|c|c|}
\hline $\begin{array}{l}\text { Dependent variable: } \\
\Delta \Delta \log \text { (NewReviews) }\end{array}$ & (1) & (2) & (3) & (4) \\
\hline$\Delta \Delta$ Free & $\begin{array}{c}1.199 * * * * \\
(0.176)\end{array}$ & $\begin{array}{c}1.178 * * * \\
(0.160)\end{array}$ & $\begin{array}{l}0.696^{*} \\
(0.423)\end{array}$ & $\begin{array}{l}0.763^{*} \\
(0.417)\end{array}$ \\
\hline$\Delta \Delta \log ($ Volume $)$ & & $\begin{array}{c}0.190^{* * * *} \\
(0.060)\end{array}$ & $\begin{array}{r}0.227^{* *} \\
(0.114)\end{array}$ & $\begin{array}{l}0.232^{* *} \\
(0.108)\end{array}$ \\
\hline$\Delta \Delta$ Dispersion & & $\begin{array}{c}-0.230 * * * \\
(0.064)\end{array}$ & $\begin{array}{c}0.069 \\
(0.122)\end{array}$ & $\begin{array}{c}0.089 \\
(0.124)\end{array}$ \\
\hline$\Delta \Delta$ Free* $\log ($ Volume $)$ & & & $\begin{array}{l}-0.029 \\
(0.111)\end{array}$ & $\begin{array}{l}-0.030 \\
(0.106)\end{array}$ \\
\hline$\Delta \Delta$ Free $^{*}$ Dispersion & & & $\begin{array}{l}-0.364^{*} \\
(0.215)\end{array}$ & $\begin{array}{l}-0.371^{*} \\
(0.208)\end{array}$ \\
\hline$\Delta \Delta \log (\text { Volume })^{*}$ Dispersion & & & $\begin{array}{l}-0.129^{*} \\
(0.067)\end{array}$ & $\begin{array}{c}-0.140 * * \\
(0.064)\end{array}$ \\
\hline$\Delta \Delta$ Free* $\log ($ Volume $) *$ Dispersion & & & $\begin{array}{l}0.152^{*} \\
(0.080)\end{array}$ & $\begin{array}{l}0.151^{*} \\
(0.077)\end{array}$ \\
\hline$\Delta \Delta$ Rating & & & & $\begin{array}{l}-0.019 \\
(0.059)\end{array}$ \\
\hline$\Delta \Delta$ OverallTop500 & & $\begin{array}{c}0.365 * * * \\
(.077)\end{array}$ & & $\begin{array}{c}0.363 * * * \\
(0.074)\end{array}$ \\
\hline$\Delta \Delta$ CategoryTop 500 & & $\begin{array}{c}0.136^{* * * *} \\
(0.026)\end{array}$ & & $\begin{array}{c}0.137 * * * \\
(0.027)\end{array}$ \\
\hline Observations & 5,665 & 5,665 & 5,665 & 5,665 \\
\hline $\mathrm{R}$-square & 0.016 & 0.024 & 0.026 & 0.032 \\
\hline
\end{tabular}

Notes: Robust standard errors in parentheses; ${ }^{* * *} p<0.01, * p<0.1$; the sign of the three-way interaction $\Delta \Delta$ Free* $\log (\text { Volume })^{*}$ dispersion is positive due to the continuous measure of volume (by contrast, we employed a binary measure that is equal to one for low volume and zero for high volume in the baseline model); caution should be taken interpreting these results, due to high correlations between $\Delta \Delta$ Free and its interactions with volume and dispersion.

Table F-2: Marginal Effects Based on Continuous Measures of Volume and Dispersion

\begin{tabular}{|c|c|c|c|}
\hline \multicolumn{4}{|c|}{ Effects of changing from paid to free on new posts } \\
\hline $\begin{array}{l}\text { Low Volume }+ \\
\text { Low Dispersion }\end{array}$ & $\begin{array}{l}\text { Low Volume + } \\
\text { High Dispersion }\end{array}$ & $\begin{array}{l}\text { High Volume + } \\
\text { Low Dispersion }\end{array}$ & $\begin{array}{l}\text { High Volume + } \\
\text { High Dispersion }\end{array}$ \\
\hline $\begin{array}{l}.868^{*} \\
(.477)\end{array}$ & $\begin{array}{l}.671^{*} \\
(.403)\end{array}$ & $\begin{array}{l}.815^{*} \\
(.403)\end{array}$ & $\begin{array}{l}.677^{*} \\
(.348)\end{array}$ \\
\hline
\end{tabular}

Notes: Marginal effects are calculated based on estimates in column (4) of Table F-1; robust standard errors in parentheses; $* p<0.1$; high volume (dispersion) is evaluated at one SD above the mean, and low volume (dispersion) is evaluated at one standard deviation below the mean. 
Table F-3: Subsample Analysis

\begin{tabular}{|c|c|c|c|c|}
\hline $\begin{array}{l}\text { Dependent variable: } \\
\Delta \Delta \log (\text { NewReviews })\end{array}$ & (1) & (2) & (3) & (4) \\
\hline$\Delta \Delta$ Free & $\begin{array}{c}1.116^{* * * *} \\
(0.269)\end{array}$ & $\begin{array}{c}1.156^{* * * *} \\
(0.259)\end{array}$ & $\begin{array}{c}1.106 * * * \\
(0.264)\end{array}$ & $\begin{array}{c}1.162^{* * * *} \\
(0.254)\end{array}$ \\
\hline$\Delta \Delta \mathrm{LV}$ & & $\begin{array}{l}-0.230^{*} \\
(0.117)\end{array}$ & $\begin{array}{l}-0.227 \\
(0.188)\end{array}$ & $\begin{array}{l}-0.247 \\
(0.185)\end{array}$ \\
\hline$\Delta \Delta \mathrm{HD}$ & & $\begin{array}{l}-0.006 \\
(0.081)\end{array}$ & $\begin{array}{l}-0.186 \\
(0.273)\end{array}$ & $\begin{array}{l}-0.196 \\
(0.261)\end{array}$ \\
\hline$\Delta \Delta$ Free $* L V$ & & & $\begin{array}{l}-0.001 \\
(0.229)\end{array}$ & $\begin{array}{c}0.002 \\
(0.223)\end{array}$ \\
\hline$\Delta \Delta$ Free*HD & & & $\begin{array}{c}0.072 \\
(0.300)\end{array}$ & $\begin{array}{c}0.156 \\
(0.289)\end{array}$ \\
\hline$\Delta \Delta \mathrm{LV} * \mathrm{HD}$ & & & $\begin{array}{c}0.414 \\
(0.299)\end{array}$ & $\begin{array}{c}0.571 * * \\
(0.289)\end{array}$ \\
\hline$\Delta \Delta$ Free $*$ LV $*$ HD & & & $\begin{array}{l}-0.583^{*} \\
(0.342)\end{array}$ & $\begin{array}{c}-0.670^{* *} \\
(0.329)\end{array}$ \\
\hline$\Delta \Delta$ Rating & & $\begin{array}{l}0.351 * * \\
(0.137)\end{array}$ & & $\begin{array}{c}0.380 * * * \\
(0.145)\end{array}$ \\
\hline$\Delta \Delta$ OverallTop500 & & $\begin{array}{c}0.446 * * * \\
(0.092)\end{array}$ & & $\begin{array}{c}0.454 * * * \\
(0.093)\end{array}$ \\
\hline$\Delta \Delta$ CategoryTop500 & & $\begin{array}{c}0.147 * * * \\
(0.044)\end{array}$ & & $\begin{array}{c}0.142 * * * \\
(0.044)\end{array}$ \\
\hline $\begin{array}{l}\text { Observations } \\
\text { R-square }\end{array}$ & $\begin{array}{l}1,952 \\
0.019\end{array}$ & $\begin{array}{l}1,952 \\
0.048\end{array}$ & $\begin{array}{l}1,952 \\
0.028\end{array}$ & $\begin{array}{l}1,952 \\
0.053\end{array}$ \\
\hline
\end{tabular}

Notes: The subsample is composed of apps whose prior average rating was at least four at both Google Play and Apple's App Store; Robust standard errors in parentheses; *** $p<0.01$, ** $p<$ $0.05, * p<0.1 ; \Delta \Delta$ indicates differences between the two platforms and between the two points in time.

Table F-4: Marginal Effects Based on Subsample Analysis

\begin{tabular}{|c|c|c|c|}
\hline Effects of changing & from paid to free on new posts & \multicolumn{3}{|l|}{} \\
\hline Low Volume + & Low Volume + & High Volume + & High Volume + \\
Low Dispersion & High Dispersion & Low Dispersion & High Dispersion \\
\hline $1.164^{* * *}$ & $0.650^{*}$ & $1.162^{* * *}$ & $1.317^{* * *}$ \\
$(0.309)$ & $(0.347)$ & $(0.254)$ & $(0.395)$ \\
\hline
\end{tabular}

Notes: Marginal effects are calculated based on estimates in column (4) of Table F-3; robust standard errors in parentheses; ${ }^{* * *} p<0.01, * * p<0.05, * p<0.1$. 
Table F-5: Cross-Sectional Analysis

\begin{tabular}{|c|c|c|c|c|}
\hline $\begin{array}{l}\text { Dependent variable: } \\
\Delta \log \text { (NewReviews) }\end{array}$ & (1) & (2) & (3) & (4) \\
\hline$\Delta$ Free & $\begin{array}{c}1.455^{* * * *} \\
(0.100)\end{array}$ & $\begin{array}{c}1.382^{* * * *} \\
(0.091)\end{array}$ & $\begin{array}{c}1.636 * * * \\
(0.105)\end{array}$ & $\begin{array}{c}1.763 * * * \\
(0.103)\end{array}$ \\
\hline$\Delta \mathrm{LV}$ & & $\begin{array}{l}-1.262 * * * \\
(0.041)\end{array}$ & $\begin{array}{c}-1.076^{* * * *} \\
(0.071)\end{array}$ & $\begin{array}{c}-0.986 * * * \\
(0.070)\end{array}$ \\
\hline$\Delta \mathrm{HD}$ & & $\begin{array}{l}-0.023 \\
(0.035)\end{array}$ & $\begin{array}{c}-0.326^{* * * *} \\
(0.086)\end{array}$ & $\begin{array}{c}-0.202 * * \\
(0.086)\end{array}$ \\
\hline$\Delta$ Free*LV & & & $\begin{array}{c}-0.734 * * * \\
(0.100)\end{array}$ & $\begin{array}{c}-0.712 * * * * \\
(0.099)\end{array}$ \\
\hline$\Delta$ Free*HD & & & $\begin{array}{l}-0.041 \\
(0.104)\end{array}$ & $\begin{array}{l}-0.068 \\
(0.102)\end{array}$ \\
\hline$\Delta \mathrm{LV} * \mathrm{HD}$ & & & $\begin{array}{c}0.560 * * * \\
(0.097)\end{array}$ & $\begin{array}{c}0.538^{* * * *} \\
(0.097)\end{array}$ \\
\hline$\Delta$ Free*LV*HD & & & $\begin{array}{l}-0.205^{*} \\
(0.123)\end{array}$ & $\begin{array}{c}-0.244 * * \\
(0.122)\end{array}$ \\
\hline$\Delta$ Rating & & $\begin{array}{c}0.184 * * * \\
(0.024)\end{array}$ & & $\begin{array}{c}0.193^{* * * *} \\
(0.023)\end{array}$ \\
\hline$\Delta$ OverallTop500 & & $\begin{array}{c}0.707^{* * *} \\
(0.104)\end{array}$ & & $\begin{array}{c}0.742 * * * \\
(0.103)\end{array}$ \\
\hline$\Delta$ CategoryTop500 & & $\begin{array}{c}0.284 * * * \\
(0.036)\end{array}$ & & $\begin{array}{c}0.254 * * * \\
(0.036)\end{array}$ \\
\hline Observations & 5,665 & 5,665 & 5,665 & 5,665 \\
\hline $\mathrm{R}$-square & 0.053 & 0.225 & 0.231 & 0.256 \\
\hline
\end{tabular}

Notes: Robust standard errors in parentheses; $* * * p<0.01,{ }^{* *} p<0.05, * p<0.1 ; \Delta$ indicates the difference between the two platforms. Results are based on the September 2014 sample and specification (2) in Study 4.

Table F-6: Marginal Effects Based on Cross-Sectional Analysis

\begin{tabular}{|c|c|c|c|}
\hline \multicolumn{6}{|c|}{ Effects of changing } & from paid to free on new posts \\
\hline Low Volume + & Low Volume + & High Volume + & High Volume + \\
Low Dispersion & High Dispersion & Low Dispersion & High Dispersion \\
\hline $1.051^{* * *}$ & $0.740^{* * *}$ & $1.763^{* * * *}$ & $1.695^{* * *}$ \\
$(0.103)$ & $(0.100)$ & $(0.103)$ & $(0.109)$ \\
\hline
\end{tabular}

Notes: Marginal effects are calculated based on estimates in column (4) of Table F-5; robust standard errors in parentheses; $* * * p<0.01, * * p<0.05, * p<0.1$. 